NBER WORKING PAPER SERIES

\title{
IMPERFECT CONTRACT ENFORCEMENT
}

\author{
James E. Anderson \\ Leslie Young
}

Working Paper 8847

http://www.nber.org/papers/w8847

\author{
NATIONAL BUREAU OF ECONOMIC RESEARCH \\ 1050 Massachusetts Avenue \\ Cambridge, MA 02138 \\ March 2002
}

This paper began while Anderson visited the Chinese University of Hong Kong,whose support and hospitality is gratefully acknowledged. Earlier versions were presented to the NBER Summer Institute, and the Econometric Society and in seminars at the University of Copenhagen, Rice University and the University of Texas-Austin. Helpful comments from participants are gratefully acknowledged, especially Jonathan Eaton and Nobuhiro Kiyotaki. The views expressed herein are those of the authors and not necessarily those of the National Bureau of Economic Research.

(C) 2002 by James E. Anderson and Leslie Young. All rights reserved. Short sections of text, not to exceed two paragraphs, may be quoted without explicit permission provided that full credit, including $(\mathrm{C}$ notice, is given to the source. 
Imperfect Contract Enforcement

James E. Anderson and Leslie Young

NBER Working Paper No. 8847

March 2002

JEL No. F10, L14

\begin{abstract}
We model imperfect contract enforcement when repudiators and their victims default to spot trading. The interaction between the contract and spot markets under improved enforcement can exacerbate repudiation and reduce contract execution, harming all traders. Improved contract execution benefits traders on the excess side of the spot market by attracting potential counter-parties, but harms them by impeding their exit from contracts found to be unfavorable. Multiple equilibria and multiple optima are possible, with anarchy a local optimum, perfect enforcement a local minimum and imperfect enforcement a global optimum. LDCs exhibit parameter combinations such that imperfect enforcement is optimal from their side of international markets. The model thus rationalizes the internationally varying patterns of imperfect enforceability observable in survey data.
\end{abstract}

James E. Anderson

Department of Economics

Boston College

Chestnut Hill, MA 02467

and NBER

James.Anderson.1@bc.edu
Leslie Young

Asia Pacific Institute of Business and Finance Department Chinese University of Hong Kong APIB, 2/F, Li Dak Sum Building CUHK, NT, Hong Kong leslieyoung@cuhk.edu.hk 
The reliability of contract enforcement varies widely across countries according to opinion surveys of traders, resulting in significant reduction of trade (Anderson and Marcouiller, 2001). Why do many countries fail to develop institutions that ensure contract enforcement, thereby garnering the full gains from trade? One possibility is that the ruling elite benefits from a pliant judiciary and contractual chaos and thus has little incentive to foster the rule of law. However, even such an elite could gain by ensuring contract enforcement in a sphere such as international trade, which yields taxable activities and business opportunities. Another possible explanation is institutional incapacity: lack of skilled personnel, professional norms and organizational frameworks. Yet, many less developed countries (LDCs) with generally weak institutions operate free trade zones with transparent business environments, which could presumably be extended to all international trade if that were expedient. Therefore, the imperfect contract enforcement often observed in LDCs might be due, not just to institutional incapacity or a Machiavellian political elite, but to the short-term interests of LDC traders.

The key to our story is the general equilibrium interactions amongst contract defaulters and their victims, both before and after default. In our model, traders negotiate contracts before sinking the costs of entering a market, but can find these contracts unenforced if repudiated. Defaulters and victims can resort to a spot market where their sunk costs are irrelevant to the outcome of one-on-one bargaining. This market generally fails to equilibrate, implying a transactions inefficiency, as some traders return home empty handed. Traders can switch between the contract and spot markets, both before and after the disturbances to their fallback options that motivate contract repudiation.

The general equilibrium effects of improved contract enforcement can increase the rate of contract repudiation, so that fewer contracts are executed. This harms traders on the scarce side of the spot market and perhaps the excess side also. For changes close to an equilibrium, this can occur only if the equilibrium is unstable. However, improved enforcement could also reduce contract execution via a jump between the stable equilibria that necessarily bracket the unstable equilibrium. Such perversities arise when the disturbances to scarce side traders fallback options have a heavy concentration well above their mean: an upside shock, as occurs in lognormal disturbances of sufficiently high coefficient of variation. Such shocks can arise endogenously when the disturbances are to the costs of processing the good for re-sale.

Separately, each excess side trader exerts an externality on the others by reducing their 
probability of matching. Improved contract execution alleviates this congestion by attracting more scarce side traders, but impedes exit from contracts found to be unfavorable, worsening excess siders expected terms of trade. For excess siders, this can mean that:

(i) perfect execution is worse than a range of high but imperfect levels of contract execution and/or:

(ii) zero execution is better than a range of low levels of imperfect execution, even though:

(iii) perfect execution is better than zero execution and between these two situations, the profits of an excess side monopsonist (monopolist) would fall as the price falls (rises).

In contexts (like international trade) where either buyers or sellers could veto changes in enforcement, these results offer insights into why contract enforcement often remains imperfect, despite the gains from trade foregone. For example, China, India or Russia would appear to have the institutional capacity to enforce all international contracts, yet choose not to do so perfectly. (i) and (iii) indicate that this policy could be in their overall interests, even when they have too little market power to gain from the improved terms of trade that would result from a reduced execution rate. Many Fourth World countries with little market power show no movement toward enforcing international contracts, despite sermons from the World Bank about the gains that await them from the foreign trade and investment that would be attracted by better enforcement. (ii) and (iii) indicate that the small improvements that can realistically be achieved by a Fourth World country might leave it worse off than zero enforcement, even when the large improvements envisaged by the World Bank would indeed make it better off. Our analysis also applies to domestic markets in the plausible case where the traders on the side of the market with greater individual bargaining power dominate institutional development because they are politically more effective.

When (i), (ii) and (iii) occur in conjunction with upside shocks to scarce siders fallback options, incremental enforcement improvements could cause excess siders expected profits to jump downward or could sharply reverse their previous gains, even within a conventionally smooth economic structure. This possibility would make excess siders even warier of improving enforcement. Indeed, given upside shocks, incremental enforcement improvements could cause downward jumps in the expected profits of all traders.

Section 1 presents the core of our analysis. Section 2 motivates, sets out and solves our formal model. Section 3 analyzes how enforcement affects contract execution and identifies 
perverse effects on scarce side traders. Section 4 shows how improved contract execution can have effects (i) - (iii) above and integrates these results with those of Section 3. Section 5 applies our results to explain the levels of contract enforcement observed in LDC trade. Section 6 considers the long-term impact of improved enforcement and suggests interpretations of the historical evolution of contract enforcement. Section 7 discusses the wider implications of our analysis for institutional evolution and future research directions.

\section{Analytical Summary}

Risk neutral agents trade in a market for contracts to deliver a good, at a price that is set before trading costs have been sunk, or in a spot market before or afterwards. A buyer can re-sell the good at home for a gross benefit that is subject to random disturbances; his net benefit is computed by subtracting the price that he has to pay, as well as his trading cost (which differs across buyers). A seller can procure the good at home at a cost that is subject to random disturbances; his net benefit from trade equals the price he receives, less his procurement cost and trading cost (which differs across sellers). The schedules of trading costs across traders define the ex ante demand and supply schedules, i.e., the schedules when buyers gross benefits and sellers procurement costs take their expected values.

Contracts are signed and trading costs sunk on the basis of traders expected net benefits from trade. The disturbances to traders gross benefits/procurement costs are then realized; traders who realize disturbances less favorable than some cutoff level repudiate their contracts. Only a parametric proportion of repudiated contracts are enforced. Repudiators who evade enforcement, as well as their victims, can resort to the spot market, where there can also be traders who chose not to contract.

On the spot market, traders are matched once for a price negotiation, whose outcome depends only on the fallback options defined by the gross benefit/ procurement cost that the negotiators realize, not on their sunk trading costs. The probability of a match depends on the ratio of buyers to sellers on the spot market, some there by choice, others through contract repudiation. The spot market is generally not in equilibrium ex post; it equilibrates ex ante in the sense that traders shift between the spot and the contract markets until their expected profits are the same in the two markets.

Via this equilibrium condition, traders beliefs about the rate of contract execution determine the cutoff values of their fallback options at which they repudiate their contracts; 
the level of enforcement then determines the actual rate of contract execution. Under rational expectations, a given level of enforcement can be compatible with multiple rates of execution when these rates are highly sensitive to the cutoff value of the fallback options. This would be true when, on the scarce side of the spot market, the disturbances to traders fallback options have a heavy concentration well above their mean: an upside shock. In this case, greater enforcement could increase the rate of repudiation of contracts, so that fewer are executed. This would certainly harm traders on the scarce side of the spot market. Figure 1 shows the various ways that the enforcement rate can affect contract execution and scarce siders profits.

Traders on the excess side can also be harmed by better enforcement, whether or not this increases the rate of contract execution. Consider an excess demand equilibrium, i.e., an ex ante equilibrium in which there is excess demand in the spot market. Improved contract execution harms buyers directly by impeding exit from contracts found to be unfavorable, thereby worsening their expected terms of trade; but benefits buyers indirectly as more sellers are attracted by the higher price that they expect; buyers are harmed overall if the supply elasticity is low. Further analysis reveals that the effect of improved contract execution on aggregate buyers profits (which are monotonic in individual buyer s ex ante profits) is like the effect of a price rise on a monopsonist. However, the price that buyers expect to pay differs from the price that sellers expect to receive because some buyers who repudiate their contracts fail to match on the spot market and end up buying on their home market. Thus, the composite elasticity determining whether buyers are harmed by improved contract execution is the ex ante supply elasticity multiplied by the ratio of the elasticities of the buyers and the sellers expected prices with respect to the rate of execution. This ratio can be greater than or less than 1 according to the stochastic structure of buyers gross benefits, which determines how changes in the rate of execution affect their decisions to repudiate.

Only the ex ante supply elasticity appears in the condition determining buyers ranking of zero and perfect execution (since both regimes preclude switches between the contract and spot markets), whereas the composite elasticity inserted into the same condition determines the impact of incremental improvements in the rate of contract execution. The discrepancy between the two elasticities admits a variety of cases (see Figure 2) where the effects of a small improvement in contract execution are opposite to those of a large improvement, such 
as that from zero to perfect execution. The requisite conditions on model parameters feature the riskiness of gross buyer benefits relative to the level of their net benefits. These conditions are compatible with the upside shocks to buyer benefits that admit multiple values of contract execution for a given enforcement rate, opening the door to complex comparative statics as enforcement increases. Figures 1 and 3 provide overviews of the possible outcomes.

\section{The Model}

\subsection{Model Motivation}

Motivated by the frequent incidence of imperfect contract enforcement in the real world, we seek a model of trade where perfect enforcement is better than zero enforcement for both sides of the market, yet for one side, imperfect enforcement can be (i) better than certain enforcement and/or (ii) worse than no enforcement. This calls for a model with the following four elements. Firstly, to motivate the use of contracts, we assume that trade imposes costs that are sunk at the time of exchange: setting up a trading infrastructure, acquiring information, packaging, shipping, etc. ${ }^{1}$ Contracts address the threat of holdup, i.e., ex post bargaining that ignores the counter-party s sunk costs. Secondly, to motivate contract violations, our model assumes that, after the contracts have been signed, each trader s net benefits of trade are subject to independent random disturbances that lead some to repudiate their contracts. Thirdly, we admit imperfect contract enforcement, parameterized as the probability that a repudiated contract will be enforced. Contracts are inherently incomplete in that it is impossible to contract on the effectiveness of the enforcement system. ${ }^{2}$

Finally, we assume that traders who repudiate their contracts, as well as their victims, can resort to a spot market where sunk trade costs are irrelevant. This is perhaps the most parsimonious way to capture general equilibrium interactions amongst traders with enforced and unenforced contracts in a way that permits imperfect enforcement to be in the interests of at least one side of the market. Appendix B on alternative trading mechanisms argues that if the victim of a repudiated, unenforced contract cannot renegotiate with anyone but is thrown

\footnotetext{
${ }^{1}$ Roberts and Tybout (1997); Bernard and Wagner (1998) document that sunk trade costs are large.

${ }^{2}$ In contrast, the complete contracts literature analyzes optimal (and implicitly perfectly enforceable) contracts but limits what attributes of a transaction can be contracted. McLaren (1998) analyzes trade and contract limitations. The incomplete contract approach can be simultaneously criticized as hand-waving and defended as realistic (Tirole, 1999). We use it for tractability and discuss robustness of the model in Appendix B.
} 
back onto his home market, then the ex ante profits of all traders would increase monotonically with improvements in contract enforcement. Moreover, if the victim can renegotiate only with the repudiator, then the contract price is efficient and ex ante profits are unchanged by improvements in enforcement; the enforcement level would affect only ex post profits. It is the possibility of the victim re-negotiating on the spot market, where he might meet a counter-party who never contracted, that makes the problem of imperfect enforcement interesting, for it leads to feedbacks between the spot and contract markets that admit multiple equilibria and a non-monotonic relationship between the ex ante profits of traders and the rate of contract execution. Appendix B also notes that contract repudiators cannot prevent a spot market by offering victims an advance payment to refrain from searching there.

Our model is otherwise kept simple to focus attention on the feedbacks between the contract and spot markets. We assume that a trader s fallback option is to trade at home at an exogenous price. Search on the spot market is simplified to a matching mechanism where the objective probability of matching is the ratio of aspiring traders from the two sides of the market. Bargaining is simplified to the Nash form, whose outcome depends on the fallback options of the two parties and on an index of their relative bargaining power. Such simplifications cleanly reveal mechanisms that must be at work in more realistic models.

\subsection{The Trading Mechanism}

Risk neutral buyers and sellers meet to exchange a good in a trading zone which they enter at a deterministic cost that generally differs from trader to trader. The trading cost schedules determine the ex ante demand and supply schedules, as further explained in Section 2.5. Each buyer buys one unit of the good, which accounts for an infinitesimal share of the market. A buyer anticipates re-selling the purchased unit back in his home market at a price $b+\mu$; a seller anticipates procuring the good in his home market at a price $c-v$. Here, $\mathrm{b}$ and $\mathrm{c}$ are fixed numbers; $\mu, v$ are random disturbances with zero means, unknown at the time that the traders have to sink their costs of entering the trading zone, but realized immediately afterward. The disturbances $\mu(v)$ for the various buyers (sellers) are identically distributed and all disturbances are pairwise independent. A buyer who enters and executes a deal at price $p$ receives payoff $b+\mu-p$; a buyer who enters, but executes no deal, returns home to buy the 
good at $b+\mu$ and receives zero payoff. A seller who enters and executes a deal receives payoff $p-c+v$; a seller who enters, but does not execute, returns home to resell the good at $c-v$ and receives zero payoff.

Before sinking trading costs, each trader can enter into a contract to deliver the good. The market mechanism for such contracts costlessly determines a market-clearing price. Once he learns his own benefit/cost disturbance, each party to a contract must decide whether or not to repudiate it, knowing the probability distributions of disturbances of all traders, but not the disturbance suffered by his counter-party. The victim appeals to a court, which, however, enforces only a parametric proportion $\theta \in[0,1]$ of the repudiated contracts. The victim of a repudiated, unenforced contract must choose between (i) renegotiating with the repudiator, (ii) returning to his home market or (iii) entering the spot market.

We open our analysis of traders decisions under the interim assumptions:

(2.1) The victim of a repudiated, unenforced contract enters the spot market, i.e., he neither renegotiates with the repudiator nor goes home.

(2.2) Traders who would be on the scarce side of the spot market never repudiate a contract.

These assumptions will be maintained until Lemmas 3 and 4, which provide conditions ensuring that these assumptions hold in a rational expectations equilibrium.

On the spot market, any trader has but one chance of being matched with a counter-party, then bargains one-on-one. Therefore, there is no mechanism to adjust the spot price after the disturbances: the typical outcome on the spot market is a mismatch between supply and demand. We assume that all scarce side traders match, but on the excess side, some must return home without trading. Excess side traders shift ex ante between the spot and the forward markets until their expected return is the same in both. This determines the contract price. In a rational expectations equilibrium, excess side traders subjective beliefs about the probability that they will match on the spot market equal the objective probability.

\subsection{Buyers}

Buyers can contract or enter the spot market directly where they seek a match with sellers. All matches result in asymmetric Nash bargaining, whose threat points are defined by the bargainers realizations of their fallback options $b+\mu$ and $c-v$. This leads to the price: 


$$
\omega(b+\mu)+(1-\omega)(c-v)
$$

where $\omega \in(0,1)$ indexes the seller s bargaining power. ${ }^{3}$ Conditional on a match, spot buyers expect to pay:

$$
p^{*} \equiv E[\omega(b+\mu)+(1-\omega)(c-v)]=\omega b+(1-\omega) c .
$$

Conditional on a failure to match, they expect to pay $b$. Therefore, a buyer who directly enters the spot market expects to pay:

$$
p^{b}=\pi p^{*}+(1-\pi) b .
$$

where $\pi$ is the probability of matching, to be determined in equilibrium.

Let $p^{C}$ be the price that would be paid by contracting buyers who execute, including those who repudiate their contracts but find them enforced nevertheless. After contracts have been signed, both parties sink the cost of entering the trading zone. Each buyer then learns the price $b+\mu$ at which he can sell the good in his home market; each (foreign) seller learns the price $c-v$ at which he can procure the good in his home market. Traders then decide whether or not to repudiate their contracts; under our interim assumptions (2.1) and (2.2), repudiators who evade enforcement and their victims then enter the spot market.

A buyer who suffers disturbance $\mu$ expects to negotiate a price $p^{*}+\omega \mu$ on the spot market if he matches; otherwise, he expects to pay $b+\mu$ on his home market. Therefore, a buyer who fails to execute his contract expects to pay $\pi\left(p^{*}+\omega \mu\right)+(1-\pi)(b+\mu)$. The disturbance at which this equals the contract price $p^{C}$ is:

$$
\mu^{*}=\frac{p^{C}-p^{b}}{\pi \omega+1-\pi} .
$$

A buyer expects to pay less than the contract price on the spot market if and only if he realizes a disturbance $\mu<\mu^{*}$. Thus, across the buyer population, the probability of repudiation is:

\footnotetext{
${ }^{3}$ This is the price $\mathrm{p}$ that maximizes $(b+\mu-p)^{\omega}(p-c+v)^{l-\omega}$. We interpret asymmetric Nash bargaining in terms of strategic play with a probability that bargaining will end. Meeting the critique of Binmore, Rubinstein and Wolinsky (1986) we suppose that the random event that ends the bargaining is a movement of price in one of the partners home markets that is more favorable to that partner than any feasible bargain. Then the other partner must return home to his fallback option. This rationalizes using traders fallback options as the threat points in Nash bargaining. (We implicitly restrict the probabilities of favorable price movements to be small enough that the expected payoff to bargaining dominates waiting for the favorable event.)
} 


$$
F\left(\mu^{*}\right) \equiv \int_{\underline{\mu}}^{\mu^{*}} f(\mu) d \mu
$$

where $f(\mu)$ is the marginal probability (density function) of $\mu$, assumed to be piecewise continuous over its support $[\underline{\mu}, \bar{\mu}]$.

We now compute the buyer s ex ante gross benefits from a contract, taking account of his option to default. Given a rate of enforcement $\theta \in[0,1]$, contracts are executed at rate:

$$
\beta=1-F+\theta F
$$

A buyer who does not execute his contract must have chosen to repudiate it. The expected value of the disturbance to his fallback options, conditional on repudiation, is the expected value of those disturbances that are less than $\mu^{*}$ :

$$
m\left(\mu^{*}\right) \equiv \int_{\underline{\mu}}^{\mu^{*}} \mu f(\mu) d \mu
$$

$m\left(\mu^{*}\right)$ is negative, being less than the zero mean of the distribution of $\mu$. The buyer expects to pay $p^{*}+\omega m\left(\mu^{*}\right)$ if he matches on the spot market; $b+m\left(\mu^{*}\right)$ if he fails to match and returns home. Thus, by (2.4), conditional on non-execution, the buyer on the contract market expects to pay:

$$
\pi\left[p^{*}+\omega m\left(\mu^{*}\right)\right]+(1-\pi)\left[b+m\left(\mu^{*}\right)\right]=p^{b}+(\pi \omega+1-\pi) m\left(\mu^{*}\right) .
$$

Overall, the buyer who contracts expects to pay:

$$
\beta p^{C}+(1-\beta)\left[p^{b}+(\pi \omega+1-\pi) m\left(\mu^{*}\right)\right]
$$

Buyers shift between the contract and the spot markets until this equals the price $p^{b}$ that they expect on the spot market if they enter it directly, i.e., until:

$$
p^{C}-p^{b}=-m\left(\mu^{*}\right)(\pi \omega+1-\pi)(1-\beta) / \beta>0 \text { for } \beta<1 .
$$

(2.7) is the premium over the expected spot price that buyers are willing to pay for a contract, because if they suffer an unfavorable benefit disturbance, then they have the option to repudiate the contract and seek a lower spot price. Eliminating $p^{C}$ between (2.5) and (2.7), we conclude that equilibrium between the contract and the spot markets requires that:

$$
-\frac{\mu^{*}}{m\left(\mu^{*}\right)}=\frac{1-\beta}{\beta} \text {. }
$$


This determines the critical value $\mu^{*}=\mu(\beta)$ compatible with equilibrium, given an execution rate $\beta \in[0,1]$.

We can solve for the contract price as a function of $\theta$ by noting that, in equilibrium, the rate of execution $\beta$ must generate a repudiation rate $F(\mu(\beta))$ via (2.8) that confirms (2.6), i.e.:

$$
1-\beta=(1-\theta) F(\mu(\beta))
$$

Lemma 1: (A) For $\beta \in[0,1]$, there exists a unique $\mu(\beta)$ satisfying (2.8). $\mu(0)=\bar{\mu}, \mu(1)=0$.

(B) For $\theta \in[0,1]$, there exists a $\beta(\theta) \in[0,1]$ satisfying (2.9). $\beta(0)=0, \beta(1)=1$.

Lemma 1 determines a $\mu(\beta(\theta))$ compatible with equilibrium in the contract market. This depends only on the distribution of benefit disturbances $\mu$ and the parametric rate of enforcement $\theta$ : it does not depend on the probability $\pi$ of a match, nor on sellers bargaining power $\omega$. Then $\mu(\beta(\theta))$ determines equilibrium values for $F$ and $m$. Henceforth, $\mu, F$ and $m$ shall be understood to take these equilibrium values, unless other arguments of these functions are specified. Given buyer beliefs about $\pi, p^{C}$ is then determined by (2.7) and (2.4).

\subsection{Sellers}

The above calculation allows for excess demand in the spot market $(\pi<1)$ as well as excess supply $(\pi=1)$. A symmetrical derivation is possible for sellers. Below, we present the sellers decisions only for the case where the spot market equilibrium exhibits excess demand. We can show that sellers then always sign contracts.

The proportion of buyers in the spot market who have defaulted on contracts equals the ratio of seller victims of default to total buyers in the spot market. Our interim assumption that traders who would be on the short side of the spot market never repudiate contracts implies that this ratio equals $\pi$, the buyer s probability of matching on the spot market. Defaulting buyers suffer a benefit disturbance of $m<0$ on average, so the impact of their disturbances on the spot price that sellers expect to negotiate is $\omega \pi m$. Seller victims of default expect to receive $p^{*}+\pi \omega m$, so sellers with a contract expect to receive: 


$$
p^{s}=\beta p^{C}+(1-\beta)\left(p^{*}+\pi \omega m\right) .
$$

Solving (2.7) for $p^{C}$ and substituting into (2.10):

$$
p^{s}=\beta p^{b}+(1-\beta) p^{*}-m(1-\beta)(1-\pi)
$$

By (2.4):

$$
p^{b}=p^{s}+(1-\beta)(1-\pi)\left(b+m-p^{*}\right)
$$

In the last term in (2.12), $b+m-p^{*}$ equals the premium over the spot price expected by buyers who avoid executing their contracts, fail to match and therefore pay their home price, which they expect to be $b+m$. $(1-\beta)(1-\pi)$ is the probability of the latter two events. Thus, $(1-\beta)(1-\pi)\left(b+m-p^{*}\right)$ is the additional amount that buyers expect to pay over what sellers expect to receive because buyers can end up purchasing at home rather than from sellers.

In an excess demand equilibrium, sellers always sign contracts because their expected price $p^{s}$ with a contract exceeds the price $p^{*}+\pi \omega m$ that they expect if they enter the spot market uncovered. This can be seen from (2.11), (2.3), (2.4) and (2.8), which imply that:

$$
\begin{aligned}
p^{s}-p^{*}-\pi \omega m & =\beta\left(p^{b}-p^{*}\right)-m(1-\beta)(1-\pi)-\pi \omega m \\
& =\beta(1-\pi)(1-\omega)(b-c)+\mu^{*} \beta[(1-\pi)+\pi \omega /(1-\beta)]>0 .
\end{aligned}
$$

\subsection{Equilibrium}

To determine equilibrium, we specify the structure of demand and supply in more detail. Risk neutral buyers demand the good (enter the trading zone) at price $p$ if their trading cost is weakly less than the gain $b-p$ that they expect. Risk neutral sellers supply the good (enter the trading zone) at price $p$ if their trading cost is weakly less than the gain $p$ - cthat they expect. Ordering buyers and sellers by increasing trading cost, let $t^{d}(q)$ be the trading cost of the marginal buyer when the total quantity bought is $q$; let $t^{s}(q)$ be the trading cost of the marginal seller when the quantity sold is $q$. The ex ante demand at price $p$ is the $d=d(p)$ such that the marginal buyer is indifferent between trading or not trading, i.e., $t^{d}(d)+b=p$. The ex ante supply at price $p$ is the $s=s(p)$ such that the marginal seller is indifferent between trading or not trading, i.e., $t^{s}(s)+c=p$.

The expected outcome of bargaining on the spot market is the $p^{*}$ specified in (2.3). If $d\left(p^{*}\right)>(=/<) s\left(p^{*}\right)$, then, absent a contract market, the spot market would exhibit excess demand (equilibrium/ excess supply). We shall show that this conclusion remains valid after the introduction of the contract market. For concreteness, we focus on the excess demand case 
where $d\left(p^{*}\right)>s\left(p^{*}\right)$; the excess supply case follows from symmetry.

In a rational expectations equilibrium, the ex ante subjective probability of a match for the excess side and of a match with a defaulter for the scarce side must equal the ex post objective probability. Thus, the equilibrium $\pi$ satisfies:

$$
\pi=h(\pi, \beta) \equiv \frac{(1-\beta) s\left(p^{s}\right)}{d\left(p^{b}\right)-\beta s\left(p^{s}\right)}
$$

The numerator on the right side equals the number of sellers who are in the spot market because their contracts were repudiated. The denominator equals the number of buyers in the spot market, i.e., the total number committed to trade, less those whose contracts are executed.

Lemma 2: If $d\left(p^{*}\right)>s\left(p^{*}\right)$, then for each $\beta \in[0,1],(2.14)$ has a unique solution $\pi[\beta] \in(0,1)$.

The $\pi$ determined by Lemma 2 defines an excess demand equilibrium. To close the model, we now state conditions ensuring that the interim assumptions (2.1) and (2.2) used so far in our analysis of individual buyers and sellers hold in a rational expectations equilibrium because they would be in the interests of the traders.

Lemma 3: In an excess demand equilibrium, a seller victimized by a repudiated, unenforced contract expects a higher payoff from entering the spot market than from renegotiating with the repudiator or returning to his home market, provided that under any cost disturbance $v$, he expects gains from spot trade. This would be true if and only if:

$$
\omega(b-c+\pi m)>-\underline{v}
$$

where $\underline{v}$ is the worst (most negative) realization of $v$.

Lemma 4: (A) In an excess demand equilibrium, a seller who learns his cost disturbance expects higher profits from honoring the contract than from entering the spot market, provided that cost disturbances are small compared to benefit disturbances, specifically:

$$
\frac{\mu(\beta(\theta)) \omega}{1-\omega}>-\underline{v}
$$

i.e., the worst cost disturbance to the seller is less than the cutoff value $\mu(\beta(\theta))$ of the buyer s benefit disturbance (at which he would be indifferent between honoring and repudiating the contract) weighted by the relative bargaining power of sellers. 
(B) If (2.15) also holds, then the seller expects higher profits from honoring the contract than from returning to his home market or renegotiating with his counter-party.

Proposition 1: Suppose that (2.15) and (2.16) hold and $\theta \in(0,1)$. If $d\left(p^{*}\right)>s\left(p^{*}\right)$, then there exists an excess demand equilibrium in which:

(i) buyers directly enter both the spot and contract markets; for some benefit disturbances, buyers with a contract repudiate it; those who evade enforcement enter the spot market;

(ii) sellers always sign contracts and never repudiate them; victims of repudiated contracts enter the spot market.

If $d\left(p^{*}\right)<s\left(p^{*}\right)$ then similar conclusions hold for an excess supply equilibrium.

Assumptions (2.15) and (2.16) will be maintained henceforth. For concreteness, the following comparative static analysis assumes an excess demand equilibrium where the sellers are on the scarce side. Similar results hold for an excess supply equilibrium.

\section{Impact of Enforcement on Contract Execution and on Sellers}

\subsection{Perverse Effects of Increased Enforcement}

We analyzed the equilibrium by determining the endogenous variables as functions of the rate of contract execution $\beta$, then determined $\beta$ as a function of the enforcement rate $\theta$. Similarly, we analyze the impact of $\theta$ on the endogenous variables via $\beta$. A subscript indicates partial differentiation with respect to the corresponding variable; for functions with only one argument (such as $\mu(\beta(\theta)), m(\mu(\beta))$ or $F(\mu(\beta))$ ), a subscript indicates total differentiation.

Lemma 5: $\mu_{\beta}<0, m_{\beta}<0$, and $F_{\beta}<0$.

Thus, key endogenous variables are monotonic in $\beta$. However, $\beta$ itself need not be monotonic in $\theta$. Recall:

$$
1-\beta=(1-\theta) F(\mu(\beta)) .
$$

The left side is the subjective non-execution probability; the right side is the objective nonexecution probability, given the subjective non-execution probability. An increase in $\theta$ decreases the objective probability of non-execution below the subjective probability. How 
must $\beta$ change to restore equality? An increase in $\beta$ decreases 1 - $\beta$, but also decreases $\mu(\beta)$ and hence $F(\mu(\beta))$. If its proportional impact on $F(\mu(\beta))$ is stronger than on 1 - $\beta$, then equality could be restored only by a decrease in $\beta$. Lemma 6 confirms this perverse outcome when $F$ is elastic to $\mu$, and excludes it when $F$ is linear in $\mu$.

Lemma 6: (A) If:

$$
\mu^{\prime} f\left(\mu^{\prime}\right)>\frac{F\left(\mu^{\prime}\right)}{1-\left\{1-F\left(\mu^{\prime}\right)\right\} \mu^{\prime} / m\left(\mu^{\prime}\right)} \text { for some } \mu \in(0, \bar{\mu}),
$$

then either $\beta_{\theta}(\theta)<0$ for some $\theta \in(0,1)$ or $\beta$ jumps upward when $\theta$ increases from 0 .

(B) $\beta_{\theta}(\theta)>0$ for all $\theta \in[0,1]$ if and only if (3.1) is reversed for all $\mu \in(0, \bar{\mu})$. This is true when $\mu$ is uniformly distributed, in which case $\beta(\theta)=\sqrt{\theta}$.

\subsection{Exogenous and Endogenous Upside Shocks}

Since the right side of (3.1) is less than 1, the hypothesis would be satisfied by a concentration of buyer disturbances at some value $\mu$ well above their (zero) mean, so that $\mu f(\mu)>1$ There are two complementary ways in which such an upside shock might arise within the i.i.d. disturbances to buyers fallback options. They could arise if each buyer comes from a locality where some political/administrative favor could permit a sharply-higher gross benefit, the windfall gains being concentrated at some level $\mu>0$. They could also arise endogenously from the economic/mathematical structure of the costs of processing the traded good for re-sale, as we now show.

Suppose that the traded good is processed using a range of local inputs, whose prices are uncertain when contracts are signed, being either exogenous or equal to their unit production costs marked up by some exogenous factor. These unit production costs in turn depend on the prices of upstream inputs, the iterative dependencies terminating in the set of direct and indirect input prices that the buyer views as exogenous, if uncertain. Suppose that all production functions are Cobb-Douglas, so that their unit cost functions are Cobb-Douglas in the input prices. By repeated substitution, the cost of processing the traded good would then be a Cobb-Douglas function of all the markup factors and exogenous input prices, i.e., the 
processing cost is the product of these terms raised to some exponent.

Suppose that this uncertain processing cost constitutes the downside disturbance $z$ from the buyer s maximum gross benefit, $b+\bar{\mu}$ so that $z$ is the product of non-negative terms $Z_{i}$, $i=1,2$, Then the $z$ with the highest marginal probability arises as the product of draws of various sizes from the various $Z_{i}$. If the $Z_{i}$ are large in number and independently distributed, ${ }^{4}$ then this modal $z$ will be much smaller than the mean $z$, which is a probability-weighted sum of terms that are dominated by the products of large draws from all the $Z_{i}$ which will be very large. Then the disturbances $\mu=\bar{\mu}-z$ to buyer benefits would have a mode $\mu=\bar{\mu}-z$ that is much larger than their mean of 0 and therefore satisfies (3.1).

This intuitive argument is supported by the Central Limit Theorem (Aitchison and Brown, Theorem 2.9, p.14), which implies that, as the number $n$ of independent disturbances $Z_{1}, . ., Z_{n}$ becomes large, their product $z_{n}$ becomes lognormal asymptotically so that its mode $z_{n}$ is indeed less than its mean. When $\ln z_{n}$ has a large variance (because $n$ is large and/or $\ln Z_{1}, \ldots, \ln Z_{n}$ have large variances), the marginal probability of the mode $z_{n}$ will be low, but the gap $\mu=\bar{\mu}-z_{n}$ between the mode and the mean will be very high. This ensures a high $\mu f(\mu)$, despite the low marginal density $f(\mu)$. This is confirmed by:

Lemma 7: If the downside disturbances $z \equiv \bar{\mu}-\mu$ from the maximum buyer s benefit $b+\bar{\mu}$ have a density function that is a lognormal, then (3.1) holds for sufficiently large values of the parameter $\sigma^{2 \circ} \equiv$ variance [lnz] that determines $z$ s coefficient of variation. ${ }^{5}$

More generally, substitutability amongst the exogenously-priced ultimate inputs to the processing of the traded good tends to make the cost multiplicative in their prices and in the markup factors in the intermediate input markets. Then the modal value of the processing cost would be well below its mean, given non-negative covariation across a large number of highly

\footnotetext{
${ }^{4}$ Our conclusions would be strengthened by positive covariation amongst the exogenous input prices and markup factors: the mean of the product of the $Z_{i}, i=1,2$, would then tend to be even larger relative to the modal value of the product. The reverse would be true if negative covariation prevailed.

${ }^{5}$ As we show in Appendix A, Lemmas 7 and 8 remain valid if the lognormal distribution of $z$ is truncated at the level $z_{0}$ that would yield zero gross benefits, and the probability mass from the right tail is compressed into a spike at $z_{0}$. This corresponds to a buyer dumping the good if gross benefits would otherwise to be negative.
} 
variable exogenous input prices and markup factors. The probability of buyer default would then be elastic to the level of buyer disturbances at their modal value, so that the execution rate can respond perversely to the enforcement rate. The consequences for the structure of equilibria are now explored.

\subsection{Instability and Multiple Equilibria Under Upside Shocks}

Perverse comparative statics, as in Lemma 6A, are often associated with instability and multiple equilibria. Local stability of our equilibrium requires the subjective non-execution probability to adjust toward its equilibrium value. Assuming that, out of equilibrium, the subjective probability adjusts toward the objective probability, local stability would require that when the subjective probability $1-\beta$ is less than its equilibrium value $1-\beta(\theta)$, then it should also be less than the objective probability, i.e., an increase in $\beta$ above $\beta(\theta)$ decreases the left side of (2.9) proportionately more than the right. This is equivalent to requiring that $\beta_{\theta}>0$.

For a given $\theta$, the equilibrium value(s) of $\beta$ are the horizontal co-ordinates of the intersection(s) of the horizontal line of height $1-\theta$ with the graph of $g(\beta) \equiv(1-\beta) / F(\mu(\beta))$. The associated equilibrium is stable if and only if this graph is negatively sloped there, so that $\beta_{\theta}>0$. Multiple equilibria correspond to multiple intersections of the graph of $g(\beta)$ with a line of height $1-\theta$. Furthermore, $\beta(\theta)$ can jump up as $\theta$ increases past 0 if $g(\beta)$ exceeds 1 for some $\beta \in(0,1)$

To relate this to hypotheses about buyer disturbances $\mu$, we use (2.8) to convert $g(\beta)$ into a function $G(\mu) \equiv 1 / F(\mu)\{1-m(\mu) / \mu\}$ of $\mu$ alone. Our taxonomy uses the following hypotheses:

[a] $G_{\mu}(\mu)>0$ for all $\mu \in[0, \bar{\mu}]$.

[b] $G_{\mu}(\mu)<0$ for some $\mu \in(0, \bar{\mu})$, but $G(\mu)<1$ for all $\mu \in(0, \bar{\mu})$.

[c] $G(\mu)<1$ near $\bar{\mu}$, but $G(\mu)>1$ for some smaller $\mu \in(0, \bar{\mu})$.

[d] $G(\mu)>1$ near $\bar{\mu}$.

(3.1) is equivalent to $G_{\mu}(\mu)<0$, so [a] rules out upside shocks. [b] - [d] require 
successively stronger upside shocks. To see this, first note that $G(\bar{\mu})=1$. If $G_{\mu}(\mu)<0$ for a range of $\mu$ below $\bar{\mu}$, then $G$ increases as $\mu$ decreases over this range. [b] holds if this range is small and/or $-G_{\mu}(\mu)$ is small, so that $G$ never increases back up to the value 1 . [c] holds if the range is extensive and/or $-G_{\mu}(\mu)$ is large, so that $G$ rises above 1. [d] holds if the range extends to all $\mu$ near $\bar{\mu}$, so that $G(\mu)$ rises above 1 near $\bar{\mu}$. Thus, [b], [c] and [d] successively require the upside shocks implied by (3.1) to be stronger and/or extend over wider ranges of $\mu$. These intuitive arguments are neatly confirmed by the lognormal model of Lemma 7:

Lemma 8: When downside disturbances from the maximum buyer s benefit $b+\bar{\mu}$ are lognormal, (3.2)[a], [b], [c], [d] arise in successively higher ranges of the parameter $\sigma$.

[Figure 1 here]

We now translate hypotheses (3.2)[a] - [d] on $G(a)$ into properties of $g(\beta)$, then explain their implications for the behavior of $\beta(\theta)$, as displayed in Figures $1[\mathrm{a}]-[\mathrm{d}]$. By(2.9), the inverse function of $g(\beta)$ defines $\beta$ as a function of $1-\theta$, so the graph of $\beta$ as a function of $\theta$ depicted in Figure 1 is the graph of $g(\beta)$ as a function of $\beta$, rotated 90 degrees anti-clockwise and shifted down by 1 to start from the origin.

[a]: $g_{\beta}(\beta)<0$ for all $\beta \in[0,1]$ so $\beta_{\theta}(\theta)>0$ for all $\theta \in[0,1]$.

[b]: The graph of $g(\beta)$ has a part that is positively sloped, but lies entirely below $1 . g(\beta)$ is continuous, $g(0)=1$ and $g(1)=0$, so $g(\beta)$ has an interior maximum $\beta_{1}$ and an interior minimum $\beta_{2}$. Let $\theta_{1} \equiv 1-g\left(\beta_{1}\right), \theta_{2} \equiv 1-g\left(\beta_{2}\right) . g\left(\beta_{1}\right)<1$ so $0<\theta_{1}<\theta_{2}<1$. $\beta(\theta)$ increases over $\left(0, \theta_{l}\right)$. As $\theta$ increases past $\theta_{l}, \beta(\theta)$ can either increase along the positively-sloped lower part of the graph or jump up to $\beta_{1}$. In $\left(\theta_{1}, \theta_{2}\right), \beta(\theta)$ can take any of the values given by the heights of the three points of the graph with horizontal co-ordinate $\theta$. The unstable equilibrium defined by the intersection with the negatively-sloped middle part is thus bracketed by intersections with the positively-sloped top and bottom parts, which define stable equilibria. 
Insofar as the equilibrium moves along the negatively-sloped middle part, $\beta(\theta)$ would decrease with $\theta$ via a local movement from one unstable equilibrium to another. However, $\beta(\theta)$ could also decrease with $\theta$ via a jump between a stable equilibrium on the top part of the graph to one on the bottom part. As $\theta$ increases past $\theta_{2}$, such a decrease in $\beta$ would be sharply reversed, as $\beta(\theta)$ jumps up to the positively-sloped top part of the graph. Multiple upside shocks to buyers would multiply the switchback pattern in $\left(\theta_{1}, \theta_{2}\right)$.

[c]: The graph of $g(\beta)$ lies below 1 for $\beta$ near 0 but rises above 1 for some larger $\beta$, so the graph must have a part that is positively sloped. Since $g(1)=0, g(\beta)=1$ for some $\beta_{3}$ and $\beta_{4}$ in $(0,1)$. The contract market would be inactive when enforcement $\theta=0$; when it is activated by an increase in $\theta$ above $0, \beta(\theta)$ could jump up from 0 to just above $\beta_{3}$ or $\beta_{4}$. The remaining remarks in [b] apply when we set $\theta_{l} \equiv 0$.

[d]: $g(\beta)>1$ for $\beta$ just above 0 . Since $g(1)=0, g(\beta)=1$ at some $\beta_{4}$ in $(0,1)$. An increase in $\theta$ above 0 would lead to an upward jump in $\beta(\theta)$ from 0 to just above $\beta_{4}$. There need not be multiple equilibria at $\theta>0$, unless there are other upside shocks.

\subsection{Impact of Enforcement on Sellers}

Lemma 9 extends the above analysis of $\beta$ as a function of $\theta$ to the sellers price $p^{s}$, hence to the typical seller s expected profits as a function of $\theta$. This leads to Proposition 2.

Lemma 9: $p_{\beta}^{s}>0$.

\section{Proposition 2:}

Hypotheses (3.2) [a] - [d] on buyer disturbances have the following implications for sellers: [a]: Improved enforcement always benefits sellers.

[b,c]: (i) At some enforcement level $\theta$, a marginal enforcement improvement could reduce seller profits. The associated equilibrium is locally unstable, but must be bracketed by stable equilibria; the marginal enforcement improvement could also reduce seller profits by 
provoking a jump from the stable equilibrium with the larger $\beta$ to the stable equilibrium with the smaller $\beta$.

[b]: (ii) There exist $0<\theta_{1}<\theta_{2}<1$ such that an increase in $\theta$ past $\theta_{1}$ could lead to a jump up in seller profits; a decrease in $\theta$ past $\theta_{2}$ could lead to a jump down in seller profits.

[c]: (ii) An increase in $\theta$ past 0 could lead to an upward jump in seller profits. There exists $0^{\circ}<\theta_{2}<1$ such that a decrease in $\theta$ past $\theta_{2}$ could lead to a jump down in seller profits.

[d]: An increase in $\theta$ past 0 certainly leads to an upward jump in seller profits.

\section{Impact of Enforcement on Buyers}

\subsection{Individual Versus Aggregate Buyer Profits}

The impact of enforcement on (excess side) buyer profits is even more complex because they need not be monotonic in the contract execution rate $\beta$. We shall analyze the impact on individual buyers via the impact on aggregate buyer profits. Since increased execution raises the price expected by suppliers, a useful benchmark for the marginal impact of execution on buyers is the marginal impact of a price rise on a monopsonist facing the same supply function $s(p)$ and the gross benefits $b$ that buyers expect on their home market. This benchmark monopsonist receives gross profits:

$$
\underline{X}(p) \equiv(b-p) s(p) \text {. }
$$

A routine calculation shows that the marginal impact of $\mathrm{p}$ on the monopsonist is given by:

$$
\underline{X_{p}}(p)<0 \text { if and only if } \varepsilon^{s}(p)<p /(b-p)
$$

where $\varepsilon^{s} \equiv p s_{p} / s$ is the elasticity of supply. A rise in $\mathrm{p}$ benefits the monopsonist by attracting more sellers, but harms it by increasing its unit procurement costs. Overall harm results if the supply elasticity is less than the ratio $p /(p-b)$ of the price to the net revenue buyers expect from trade. This behavior of $\underline{X}(p)$ as a function of $p$ foreshadows the behavior of buyers aggregate expected gross profits $X$ as a reduced form function of $\beta$, from which we can infer the behavior of individual buyer s profits, as follows.

Let the expected gross profits of a buyer be $x=(b-p)^{*} \pi$ so the price facing buyers given 
by (2.4) is $p^{b}=b-x$ Buyers aggregate gross profits are:

$$
X=x d(b-x)
$$

$X$ is strictly increasing in $x$, so the impact of execution $\beta$ on $x$ has the same sign as its impact on $X$. To compute the latter, rearrange (2.14) as:

$$
\pi=(1-\beta+\beta \pi) \frac{s}{d}
$$

which implies that:

$$
X=\left(b-p^{*}\right) \pi d=\left(b-p^{*}\right)(1-\beta+\beta \pi) s\left(p^{s}\right)
$$

By (2.12) and (2.4):

$$
p^{s}=p^{*}+(1-\pi)\left\{\beta\left(b-p^{*}\right)-(1-\beta) m\right\}=q^{s}+r
$$

where:

$$
q^{s} \equiv p^{*}+\left(b-p^{*}\right) \beta(1-\pi) \text { and } r \equiv-(1-\pi)(1-\beta) m
$$

Therefore:

$$
X=(b-\stackrel{q}{q}) s\left(p^{s}\right)=\left\{b-\left(p^{s}-r\right)\right\} s(p
$$

Thus, buyers aggregate expected gross profits equal the gross profits from purchasing the foreign units $s\left(p^{s}\right)$ at the notional price $q^{s}$ and selling them at price $b$. However, this notional price $q^{s}$ falls short of the price $p^{s}$ expected by sellers by an amount $r$. This is because some of the units that generate profits for buyers are actually purchased domestically by buyers who (i) choose to default on contracts, then (ii) fail to match with a foreign seller and so end up with gross benefits that are expected to be lower by $-m$ than the level $b$ expected by the average buyer. (4.3) has the intuitive interpretation that the shortfall $r$ in the notional price $q^{s}$ paid by buyers for the foreign units equals the probability of events (i) and (ii) times the expected home price advantage of defaulting buyers, $-m$.

\subsection{Local Impact of Contract Execution on Buyer Profits}

We now determine the impact of increased execution $\beta$ on the typical buyer s expected gross profit $x$. Let:

$$
\Delta[\beta] \equiv \frac{p_{\beta}^{s}}{p^{s}} / \frac{q_{\beta}^{s}}{q^{s}}=\frac{1+r_{\beta} / q_{\beta}}{1+r / q}
$$


be the ratio of the elasticities with respect to $\beta$ of the price $p^{s}$ faced by the seller and the price $q^{s}$ notionally paid by the buyers when $\pi$ is held constant. [ $\left.\beta\right]$ indicates a reduced form functional dependence on $\beta$.

Proposition 3: In an excess demand equilibrium $x_{\beta}[\beta]<0$ if and only if $\varepsilon^{s} \Delta[\beta]<q^{s} /\left(b-q^{s}\right)$.

The intuition is as follows. Better contract execution benefits buyers by attracting more sellers from whom to buy at the notional price $q^{s}$, but harms them by raising $q^{s}$ : they expect worse notional terms of trade, given the greater difficulty of exiting contracts found to be unfavorable. Overall, buyers are harmed if the supply elasticity is low relative to the ratio of the buyer s notional cost $q^{s}$ to notional net receipts per unit, $b-q^{s}$. The impact of increased execution on aggregate buyer gross profits (hence on individual buyer gross profits), as characterized by Proposition 3, is like the effect of a price rise on the benchmark monopsonist, as characterized by (4.2). It is more complex, however, because the notional price $q^{s}$ paid by buyers differs from the price $p^{s}$ expected by sellers which determines their supply response ${ }^{\circ}$ hence the additional term $\Delta[\beta]$ given by (4.4), which converts a given percentage increase in unit buyer notional cost into the corresponding percentage increase in unit seller receipts.

Lemma 1A shows that as $\beta \rightarrow 0$, repudiation almost always occurs and the price expected by sellers $p^{s} \rightarrow p^{*}$. As $\beta \rightarrow 1, \mu(\beta) \rightarrow 0$, i.e., almost all buyers with disturbances below the zero mean repudiate their contracts, but end up executing them anyway. Buyers and sellers with a contract expect to pay the same price $p^{C}$ so this equals the competitive equilibrium price $p^{e}$ such that $d\left(p^{e}\right)=s\left(p^{e}\right)$. The corresponding boundary values of $\Delta[\beta]$ are given by:

Lemma 10: (A) $\Delta[0]=\frac{b-p^{*}+\bar{\mu}}{b-p^{*}}>1$; (B) $\Delta[1]=\frac{b-p^{*}+m(0)}{b-p^{*}}<1$.

Lemma 10 and Proposition 3 now yield:

Proposition 4: In an excess demand equilibrium:

(A) $x_{\beta}[0]<0$ if and only if $\varepsilon^{s}\left(p^{*}\right)<\frac{p^{*}}{b-p^{*}+\bar{\mu}}$ 
(B) $x_{\beta}[1]<0$ if and only if $\varepsilon^{s}\left(p^{e}\right)<\frac{p^{e}\left(b-p^{*}\right)}{\left(b-p^{e}\right)\left\{b-p^{*}+m(0)\right\}}$

(A) states that zero execution would be a local maximum for buyers, given a supply elasticity less than the ratio of the expected spot price $p^{*}$ to the net benefit from that price to the buyer with the highest gross benefits (the first not to repudiate when enforcement rises above zero). Buyers would then oppose any policy to increase the execution rate above zero.

(B) states that perfect execution would be a local minimum for buyers, given a supply elasticity that is low relative to the product of (i) the ratio of the competitive price to the expected net buyer receipts from that price and (ii) the ratio of the net buyer benefits of trade expected at the spot price to the expected net benefits of those buyers whose disturbances are below the mean (who would all seek to default, given a marginal imperfection in enforcement). Buyers would then oppose any attempt to perfect contract execution.

\subsection{Global Impact of Execution Rate on Buyer Profits}

This sub-section considers the global impact of $\beta$ on expected buyer profits $x[\beta]$, in particular, when Proposition $4 \mathrm{~s}$ local results at $\beta=$ and $\beta=$ kwould be reversed at intermediate $\beta$, leading to an interior maximum and/or minimum. This can be determined by combining the above local analysis of $x_{\beta}[0]$ and $x_{\beta}[1]$ with a comparison of $x[0]$ and $x[1]$, as in the following Lemma, whose proof is obvious from Figure 2:

[Figure 2 here]

Lemma 11: Suppose that the cumulative distribution functions of trading costs over traders are continuous, so that $x[\beta]$ is continuous in $\beta$.

(A) If $x_{\beta}[1]<0$ and $x[0]<x[1]$, then as $\beta$ decreases from $1, x[\beta]$ increases to an interior maximum, but eventually decreases.

(B) If $x_{\beta}[0]<0$ and $x[0]<x[1]$, then as $\beta$ increases from $0, x[\beta]$ decreases to an interior minimum, but eventually increases.

(C) If $x_{\beta}[0]<0, x[0]<x[1]$, and $x_{\beta}[1]<0$, then as $\beta$ increases from $0, x[\beta]$ first decreases to an interior minimum then increases to an interior maximum before decreasing to $x[1]$. 
(D) If $x_{\beta}[0]>0$ and $x[0]>x[1]$, then as $\beta$ increases from $0, x[\beta]$ increases to an interior maximum, but eventually decreases.

The ranking of $x[0]$ and $x[1]$ can be determined by comparing the benchmark monopsonist s profits $\underline{X}(p)=(b-p) s(p)$ at the prices $p^{*}$ and $p^{e}$ that would obtain at the execution rates $\beta=0$ and $\beta=1$. This is because no buyers default at these execution rates.

Lemma 12: In an excess demand equilibrium, if $\underline{X}\left(p^{*}\right)<(>) \underline{X}\left(p^{e}\right)$ then $x[0]<(>) x[1]$.

In an excess demand equilibrium, $p^{*}<p^{e}$. If $\underline{X}(p)$ is concave in $\mathrm{p}$, then the ranking of $\underline{X}\left(p^{*}\right)$ and $\underline{X}\left(p^{e}\right)$ can be determined from the locations of $p^{*}$ and $p^{e}$ relative to the price $P^{b}$ that maximizes $\underline{X}(p)$. In particular, if $\varepsilon^{s}\left(p^{e}\right)>p^{e} /\left(b-p^{e}\right)$ then $\underline{X}_{p}\left(p^{e}\right)>0=\underline{X}_{p}\left(P^{b}\right)$. Given a concave $\underline{X}(p)$, it follows that $p^{e}<P^{b}$. Since $p^{*}<p^{e}$, it follows that $\underline{X}\left(p^{*}\right)<\underline{X}\left(p^{e}\right)$, so by Lemma 12 , $x[0]<x[1]$, as required in cases $(\mathrm{A})-(\mathrm{C})$. Lemma 11 and Proposition 4 now imply Proposition $5 \mathrm{~A}-\mathrm{C}$ below. This proposition assumes that $\underline{X}$ is concave as a function of sales, rather than as a function of $\mathrm{p}$, to ensure consistency within the hypotheses of $(\mathrm{B})$ and of $(\mathrm{C}){ }^{6}$

In case $\mathrm{D}$, note that if $p^{*}<P^{b}<p^{e}$ and $p^{*}$ is close to $P^{b}$, then $\underline{X}\left(p^{*}\right) \cong \underline{X}\left(P^{b}\right)>\underline{X}\left(p^{e}\right)$ and $x[0]>x[1]$, as hypothesized in Lemma 11D. In fact, the concavity of $\underline{X}(p)$ would then imply that $\underline{X}_{p}\left(p^{*}\right)>\underline{X}_{p}\left(P^{b}\right)=0$, so (4.2) and Proposition 4A would imply that $x_{\beta}[0]>0$, the other hypothesis of Lemma 11D. This leads to Proposition 5D.

\footnotetext{
${ }^{6}$ These hypotheses require that $\varepsilon^{s}(p)$ increase as $\mathrm{p}$ increases from $p^{*}$ to $p^{e}$. This is inconsistent with $X$ being concave in $\mathrm{p}$, but is consistent with $X$ being concave in sales. The latter hypothesis suffices for the arguments leading to Proposition 5. $x[\beta]$ would also have an interior minimum if $x_{\beta}[1]>0$ and $x[0]>x[1]$, but the hypotheses required to ensure this that correspond to those in Proposition 5B would be inconsistent.
} 
Proposition 5: Suppose that the cumulative distribution functions of trading costs over traders are continuous and that the benchmark monopsonist s profits are concave as a function of sales. In an excess demand equilibrium:

(A) If $\frac{p^{e}}{b-p^{e}}<\varepsilon^{s}\left(p^{e}\right)<\frac{p^{e}\left(b-p^{*}\right)}{\left(b-p^{e}\right)\left\{b-p^{*}+m(0)\right\}}$ then a reduction in execution rate from $\beta=1$ initially increases buyer profits $x[\beta]$, but eventually decreases them to a level $x[0]<x[1]$.

(B) If $\frac{p^{e}}{b-p^{e}}<\varepsilon^{s}\left(p^{e}\right)$ and $\varepsilon^{s}\left(p^{*}\right)<\frac{p^{*}}{b-p^{*}+\bar{\mu}}$ then an increase in execution rate from $\beta=0$ initially decreases buyer profits, but eventually increases them to a level $x[1]>x[0]$.

(C) If $\frac{p^{e}}{b-p^{e}}<\varepsilon^{s}\left(p^{e}\right)<\frac{p^{e}\left(b-p^{*}\right)}{\left(b-p^{e}\right)\left\{b-p^{*}+m(0)\right\}}$ and $\varepsilon^{s}\left(p^{*}\right)<\frac{p^{*}}{b-p^{*}+\bar{\mu}}$ then an increase in execution rate from $\beta=0$ initially decreases buyer profits, then increases them, but eventually decreases them again to a level $x[1]>x[0]$.

(D) If $p^{*}<P^{b}<p^{e}$ and $p^{*}$ is sufficiently close to $P^{b}$, then an increase in execution rate from $\beta$ $=0$ initially increases buyer profits, but eventually decreases them to a level $x[1]<x[0]$.

See Section 1 for an intuitive explanation of how the various hypotheses fit together to generate this Proposition. The bounds in (A) admit a broad range of supply elasticities, if (i) the competitive price is small relative to the net benefits of trade at this price, but (ii) the ratio $\left(b-p^{*}\right) /\left(b-p^{*}+m(0)\right)$ is large, i.e., there is substantial downside risk in net buyer benefits from spot trade in that the expected net benefits are large relative to the expected value of those net benefits that are below the mean. The bounds in (B) admit a broad range of supply elasticities if the spot price $p^{*}$ is large relative to the maximum net benefits of trade $b-p^{*}+\bar{\mu}$. Case (C) combines (A) and (B).

\subsection{Global Impact of Enforcement on Buyers}

Proposition $5 \mathrm{~s}$ conclusions about the non-monotonic impact of $\beta$ on buyer profits $x$ carry over to the impact of $\theta$ on $x$ when the equilibrium $\beta(\theta)$ is unique and increasing in $\theta$ (i.e., buyer disturbances satisfy (3.2)[a]). Outcomes are yet more complex if there are multiple 
equilibrium $\beta(\theta)$ for a given $\theta$ (i.e., buyer disturbances exhibit upside shocks satisfying (3.2) [b], [c] or [d]) while $\beta$ has a non-monotonic impact on buyer profits $\mathrm{x}$ (as in Proposition 5). Over a range of $\theta$ where $x$ is increasing in $\beta$, the graph of $x$ as a function of $\theta$ is then like Figure 1 (although it would intersect the vertical axis above the origin). Over a range of $\theta$ where $x$ is decreasing in $\beta$, the graph would look like Figure 1 flipped vertically, as in Figure 3. The analysis of Section 3 then implies that an incremental improvement in enforcement could: harm both buyers and sellers ([b,c](i)); offer buyers local gains that would be sharply reversed under further incremental improvements ([b,c](ii)); cause a downward jump in buyer profits ([b](iii)); cause a downward jump in buyer profits once contracts begin to be enforced ([c](iii), [d]).

[Figure 3 here]

\section{Proposition 6}

Hypotheses (3.2)[a] — [d] on buyer disturbances have the following implications for buyers:

[a]: Proposition 5 holds for buyer profits as a function of enforcement $\theta$.

[b,c]: (i) There exists $\theta \in(0,1)$ such that $\beta_{\theta}(\theta)<0$. If $x_{\beta}[\beta(\theta)]>0$, then a marginal improvement in enforcement above $\theta$ harms both buyers and sellers. The associated equilibrium is locally unstable, but is bracketed by stable equilibria; a small enforcement improvement could also harm both buyers and sellers by provoking a shift from the stable equilibrium with the larger $\beta$ to the stable equilibrium with the smaller $\beta$.

$[\mathrm{b}, \mathrm{c}]$ : (ii) Suppose that $x_{\beta}[\beta(\theta)]<0$ over an interval $\left(\theta_{3}, \theta_{4}\right)$ where $0 \leq \theta_{1} \leq \theta_{3}<\theta_{4} \leq \theta_{2}<1$, so that buyer s profits behave as in Figure 3[b] over this interval. An increase in $\theta$ between $\theta_{3}$ and $\theta_{4}$ could increase buyer profits through: (I) a local movement from one unstable equilibrium to another (along the positively-sloped middle part of the graph); (II) a jump from an unstable to a stable equilibrium (from the middle to the top part of the graph), or (III) a jump between stable equilibria (from the bottom to the top part of the graph). However, an increase in $\theta$ above $\theta_{2}$ would lead to a downward jump in buyer profits.

[b]: (iii) $0<\theta_{1}$ and an increase in $\theta$ past in $\theta_{1}$ could lead to an upward jump in $\beta$ (from a 
lower to an upper part of the graph in Fig. $1[\mathrm{~b}])$. If $x_{\beta}[\beta]<0$ over this range of $\beta$, then buyer profits would jump downward (Fig. $3[\mathrm{~b}]$ ).

[c]: (iii) An increase in $\theta$ past in 0 could lead to a jump upward in $\beta$ (from 0 to $\beta_{3}$ or $\beta_{4}$ in Fig. 1c). If $x_{\beta}[\beta]<0$ over this interval, then buyer profits would jump downward (Fig. $3[\mathrm{c}]$ ).

[d]: An increase in $\theta$ past 0 certainly leads to an upward jump in $\beta$ (from 0 to $\beta_{4}$ in Figure 1[d]). If $x_{\beta}[\beta]<0$ over this interval, then buyer profits would jump downward (Fig. 3[d]).

\section{Implications: Contract Enforcement and Economic Development}

The introduction asked why LDCs do not set up institutions that ensure the enforcement of international contracts. Our analysis identified circumstances where improved enforcement harms a country s traders. We now argue that these circumstances are often found in LDCs.

LDC traders are likely to be on the excess side of the spot market if their spot bargaining power is strong. Reasons why this might be so are suggested both by a formal model of bargaining and by informal considerations. In Rubinstein s (1982) formal model of bargaining as alternating offers, each agent has some chance of a very favorable price offer arriving from his home market before the next round which would cause him to exit from the bargaining. In refusing his last offer and starting another round of bargaining, his partner faces the possibility that he will exit. The bargaining power of an agent in this setup is his probability of the very favorable home price divided by the sum of the two probabilities of favorable prices. ${ }^{7}$ In LDCs, markets tend to be thin and background institutions unstable, leading to regime shifts; both factors make prices highly variable, so that the LDC trader has a high probability of a very favorable home price, hence strong bargaining power according to the formal model.

At an informal level, casual empiricism suggests that LDC traders have strong bargaining power on home turf because they can exploit local institutions and rules of the business game, ${ }^{\circ}$ which are opaque and poorly codified. Bargaining success is enhanced by personal qualities: shrewdness, charm, ruthless focus. Even if both countries have the same distribution of personalities across their populations, business competition in an LDC with weak

\footnotetext{
${ }^{7}$ As noted previously, this setup meets the critique of Binmore, Rubinstein and Wolinsky (1986) by justifying the use of fallback options as the threat points in the bargaining game.
} 
institutions is more likely to select for bargaining skills, while business competition in a developed country with strong institutions is more likely to select for other skills, such as navigating complex formal rules and managing large bureaucracies.

The above discussion leads us to focus on the case where LDC buyers are on the excess side of the market. ${ }^{8}$ We now explore the implications of our analysis for this case. Proposition 4A states that such buyers oppose initial attempts to enforce contracts if and only if the supply elasticity is less than the ratio of the autarky price to the maximum buyer benefits from trade at that price. A low price elasticity of international supply of goods to an LDC is likely since price rises cannot compensate for institutional failings that jeopardize the personal security, property and coherent management of the trade offices necessary in the LDC. The poorest LDCs, like those in Sub-Saharan Africa, provide a plausible context for spot bargaining that yields a price $p^{*}$ that is lower than the competitive equilibrium price $p^{e}$, yet is high enough that $p^{*} /\left(b-p^{*}+\bar{\mu}\right)$ exceeds the supply elasticity. In such countries, Proposition 4A predicts domestic opposition to initial attempts to enforce contracts.

Proposition 4B states that buyers would oppose attempts to perfect contract execution, if and only if the supply elasticity is less than the product of (i) the ratio $p^{e} /\left(b-p^{e}\right)$ of the competitive equilibrium price to the expected net buyer benefits from that price and (ii) the ratio $\left(b-p^{*}\right) /\left\{b+m(0)-p^{*}\right\}$ of expected net benefits from spot trade to the expected value of those net benefits that are below the mean. Ratio (ii) would be high if buyer disturbances have substantial downside risk below their mean so that $m(0)$ is strongly negative. Countries like Russia, India and China provide a plausible context for the postulated combination of spot bargaining that yields a price lower than the competitive price, a low price elasticity of supply from international sellers fearful of institutional inadequacies, and substantial downside risk to buyers. Our model predicts that such a country would not seek perfect execution of international contracts, even if the government had the requisite institutional resources.

The global analysis of Proposition 5A-C yielded parameter combinations ensuring that the above conclusions are compatible with anarchy being inferior to perfect contract execution, so that improvements in execution have a non-monotonic effect on buyer welfare. Case (C) 
yields particularly complex effects: an improvement initially harms buyers, then benefits them, then harms them as execution becomes certain. This highlights the complex ways in which incremental institutional improvements could be blocked by vested interests, even when they would gain from larger-scale improvements. The analysis also shows that two countries whose traders have similar characteristics and face similar supply conditions could end up with very different levels of contractual enforcement in international trade: one could set zero enforcement because this is a local optimum for its traders, while the other could set a positive, imperfect, level of enforcement because this is also a local optimum (or perhaps a global optimum) for its traders. Alternatively, under the same conditions, vested interests in a low enforcement country would oppose gradualist reform but support Big Bang reform.

In the opposite vein, Proposition 5D showed that initial gains to excess siders from improved enforcement could prove deceptive, being reversed by further rises in the execution rate; perfect enforcement would leave them worse off than zero enforcement. This follows from the innocuous hypothesis that spot market bargaining leads to a price just less than that charged by a monopsonist, which in turn is less than the competitive price.

LDCs offer a plausible context for each of Section $3.2 \mathrm{~s}$ accounts of how upside shocks can arise in buyer disturbances, leading to multiple equilibria and perverse outcomes. LDC businesses often operate in local environments where major political/administrative favors are dispensed, so that they could enjoy concentrated windfall gains. Where the traded good requires more complex processing, the inputs required directly and indirectly often have highly unstable prices and markups, again leading to upside shocks. Then a given enforcement $\theta$ could lead to multiple equilibrium levels of contract execution $\beta(\theta)$. Adding this complexity to the complex impact of $\beta$ on buyer profits renders even less reliable the gains from contract enforcement. We now highlight some cases.

Where better contract execution increases buyer profits, upside shocks to buyer disturbances raise the possibility that enforcement improvements would reduce contract execution by local changes from an unstable equilibrium or by jumps between equilibria that

\footnotetext{
${ }^{8}$ Similar remarks apply to the case of LDC exports to a developed country where LDC sellers are on the excess side of the market.
} 
are stable. This would harm sellers as well as buyers, rendering counter-productive seller pressure for improved enforcement. Conditions ensuring this outcome were given in Proposition 6[a].

Where better contract execution would reduce buyer profits, an upside shock to their fallback options introduces the risk that incremental enforcement improvements would result in upward jumps in contract execution, hence downward jumps in expected buyer profits. By Proposition 6, such jumps could occur for any increase in contract enforcement above 0 , given buyer disturbances satisfying [c] or [d] which always obtain in the lognormal model at sufficiently high levels of proportional uncertainty $(\sigma \neq .63)$. This prospect would be especially discouraging for LDCs considering whether to raise contract enforcement above minimal levels in a highly uncertain environment. At the other extreme, LDCs considering whether to perfect enforcement would be discouraged by the possibility that the gains from previous enforcement improvements could be sharply reversed, as in Proposition 6[b,c] (i) when $\theta$ increases above $\theta_{2}$. These cases obtain in the lognormal model at intermediate levels of proportional uncertainty $(.59 \leq \sigma \leq 1.48)$.

\section{Long-term Effects of Contract Enforcement}

This section considers the long-term effects of international contract enforcement that might operate via its impact on relative bargaining power, the foreign supply elasticity and the stochastic structure of disturbances to traders fallback options. Both our formal and informal analyses of bargaining power point to a long-term linkage to the quality of contract enforcement in international business. The mechanism is that international business standards become domestic benchmarks; institutions developed for international business come to be invoked for domestic business. In the long term, this creates a more predictable environment for domestic business as trading is codified, contracts enforced and prices reflect long-run values more closely. In the formal model of bargaining power, this would lower the LDC trader s bargaining power by lowering the probability of a very favorable price offer arriving from his home market. In our informal discussion of bargaining power, the more stable domestic environment would reduce the bargaining advantage of LDC traders by improving 
the transparency and codification of local rules of the business game. It would also reduce pressures for LDC competition to select for bargaining rather than management skills.

These arguments underpin our hypothesis that $d \omega / d \theta>0$ in the long term, i.e., improved contract enforcement in the LDC increases the bargaining power $\omega$ of foreign sellers. An LDC policy maker who holds this hypothesis would consider not only the direct effect of improved enforcement on his trader s profits, but also the indirect effects via the induced changes in their relative bargaining power. ${ }^{9}$ In an excess demand equilibrium, increased bargaining power by foreigners forces domestic buyers to pay more, but also increases the number of sellers, hence the probability of matching. If sellers are very price elastic, then this has the paradoxical consequence that buyers gain from increased foreign bargaining power.

Let $x\{\omega\}=\left(b-p^{*}\right) \pi$ be a buyer s expected gross profit as a reduced-form function of sellers bargaining power $\omega$. An analysis like that for Proposition 3 shows that:

$$
x_{\omega}\{\omega\}<0 \text { if and only if } \varepsilon^{s} \Gamma\{\omega\}<q^{s} /\left(b-q^{s}\right)
$$

where:

$$
\Gamma\{\omega\} \equiv \frac{p_{\omega}^{s}}{p^{s}} / \frac{q_{\omega}^{s}}{q^{s}}=\frac{1+r_{\omega} / q_{\omega}}{1+r / q}
$$

is the ratio of the elasticities with respect to $\omega$ of the price $p^{s}$ faced by the seller and the price $q^{s}$ notionally paid by the buyers when $\pi$ is held constant. However, when $\pi$ is held constant, $\omega$ does not affect $r \equiv-(1-\pi)(1-\beta) m$. We conclude that:

Proposition 7: In an excess demand equilibrium

$$
x_{\omega}\{\omega\}<0 \text { if and only if } \varepsilon^{s}<p^{s} /\left(b-q^{s}\right)
$$

Linking the direct and indirect effects determined by Propositions 3 and 7 is:

Lemma 13: For values of $\beta$ close to $0(1), q^{s} / p^{s}<(>) \Delta[\beta]$.

Suppose that, at high enforcement levels, an increase in enforcement increases buyer profits 
directly. Since $\beta_{\theta}(\theta)>0$ for $\theta$ close to $1^{10}$, it follows that for $\beta$ close to $1, x_{\beta}[\beta]>0$, so $\varepsilon^{s} \Delta[\beta]^{\circ}>q^{s} /\left(b-q^{s}\right)$ by Proposition 3 and $\varepsilon^{s}>p^{s} /\left(b-q^{s}\right)$ by Lemma 13. Proposition 7 implies that the increase in $\omega$ induced by the increase in $\theta$ decreases buyer profits indirectly also.

Proposition 8: Suppose that $d \omega / d \theta>0$ in an excess demand equilibrium, i.e., improved enforcement increases the bargaining power of scarce side sellers. For $\theta$ close to 1 , if an increase in $\theta$ increases expected buyer profits directly, then the induced increase in $\omega$ also increases expected buyer profits indirectly.

Thus, if a country with good enforcement improves it further in the short-term interests of its excess side traders, and this improves the bargaining position of foreigners in the long term, then this again benefits its own traders. Thus, long-term calculations would reinforce short-term ones in driving the country toward better enforcement. Similarly, Lemma 13 indicates that if a country avoids enforcing international contracts in the short-term interests of its excess side traders, then this calculation would be reinforced by the long-term effects of improved enforcement on its traders bargaining power. ${ }^{11}$

Another possible long-term effect of improved contract enforcement is via changes in the elasticity of supply. Section 5 argued that price rises would elicit little supply response from traders fearful of poor institutional environments that jeopardize the personal security, property rights and coherent management of their trade offices. Improvements in the institutional environment for foreign traders that spill into the domestic economy in the long term could therefore increase the elasticity of supply of imports. By Propositions 3 and 7 , this makes it more likely that an increase in $\beta$ or $\omega$ would increase expected buyer profits.

\footnotetext{
${ }^{9}$ Sellers always gain from increased bargaining power since this increases the expected price that they face.

${ }^{10}$ This follows because $\beta(1)=1$ but $\beta(\theta)<1$ for $\theta$ close to 1 .

${ }^{11}$ If buyer disturbances satisfy hypotheses [a] or [b] in Section 3, then $\beta_{\theta}(0)>0$. If an increase in enforcement above 0 decreases buyer s profits directly, then $x_{\beta}[0]<0, \varepsilon^{s} \Delta[0]<q^{s} /\left(b-q^{s}\right)$ by Proposition 3 and $\varepsilon^{s}<p^{s} /\left(b-q^{s}\right)$ by Lemma 13. Proposition 7 now implies that the increase in $\omega$ induced by the increase in $\theta$ decreases buyer profits indirectly also. If buyer disturbances satisfy hypotheses [c] or [d], then $\beta$ jumps upward from 0 . The same
} 
A third possible long-term effect of improved contract enforcement arises because the required institutional changes would tend to level the playing field for business by insulating it from political and administrative shocks. If this smoothes out the disturbances to traders fallback options, then it would facilitate further improvements in contract enforcement by eliminating the problems created by multiple equilibria that were analyzed in Section 3.

Thus, improved contract enforcement for foreigners could have long-term effects on the domestic environment such that further improvements in enforcement are likely to generate further short-term benefits to buyers, as well as long-term benefits as the bargaining position of foreign suppliers is strengthened. Therefore, if a country starts with circumstances that create a domestic constituency for improved contract enforcement in international trade, then there are multiple channels whereby the improved enforcement strengthens the domestic constituency for further improvements. The medieval commercial revolution of Western Europe might provide a case in point. Competition amongst European jurisdictions meant that each started facing quite high trade elasticities. Our model suggests that this created a constituency within each jurisdiction for better enforcement of contracts with foreigners which fed back on itself via the long term mechanisms discussed above, leading ultimately to the high levels of enforcement observed in modern times.

Proposition 3, Lemma 4B, Lemma 1B and Proposition 7 also imply that, when contract enforcement $\theta$ is high, we could have $x_{\beta}<0$ and $x_{\theta}<0$, but $x_{\omega}>0$. Thus, improved contract enforcement could reduce buyer profits in the short term but raise them in the long term by increasing the spot bargaining power $\omega$ of sellers. This possibility is enhanced if the improved enforcement also increases foreigners supply elasticity and smoothes out upside shocks to buyers fallback options at home. This suggests an interpretation of China s recent decision to join the WTO. China s modernization has been fuelled by international trade, yet unreliable contract enforcement has been a constant complaint of its trading partners. Thus, the shortterm interests of China s international sector have provided no domestic support for improved enforcement of international contracts. However, China s policy-makers have now recognized

argument obtains, except in the picayune case where $x_{\beta}[0]>0$, but the upward jump in $\beta$ nevertheless decreases buyer profits because $x_{\beta}(\beta)<0$ over most of the jump. 
that such improvements are likely to spill over into its domestic environment in the long term. The long-term benefits analyzed above may have helped motivate their commitment to the sharp improvements in contract enforcement required by WTO membership. ${ }^{12}$

\section{Conclusions}

In the absence of scale economies and market imperfections, standard microeconomics determines general equilibrium market outcomes as smooth functions of endowments, tastes and technology. This paper shows the complex phenomena that can emerge from general equilibrium interactions when contracts are imperfectly enforced, but the economic structure is otherwise smooth and conventional. Incorporating a spot market in which contract repudiators and their victims meet to trade is a parsimonious way to close a model of imperfect contracting, while capturing the general equilibrium effects of feedbacks between enforced and unenforced contracts. These feedbacks can lead to: (i) multiple equilibria, unstable equilibria and perverse and discontinuous dependence of contract execution on enforcement levels, when traders fallback options are subject to upside shocks; (ii) nonmonotonic dependence of trader profits on contract execution levels, with zero a local maximum and perfect execution a local minimum, given the transaction externalities in the spot market.

Thus, even in a simple economy specified by smooth functions, general equilibrium interactions subject to imperfect institutions can make the impact of institutional improvements perverse, discontinuous, multivalent and subject to reversals smooth and sharp. This reinforces a basic insight of New Institutional Economics path dependence by showing that the identification of one state of affairs as being Pareto inferior to another discretely far away is no guarantee that a political economy, let alone its institutional infrastructure, can find a path from the inferior to the superior state.

Within a unified political system, a veto of incremental institutional improvements by one side of the market could, in principle, be overcome by a government that imposes large-scale improvements from above. However, Barry Weingast has emphasized that A government strong enough to protect property and enforce contracts is also strong enough to confiscate the

\footnotetext{
${ }^{12}$ This was confirmed by Vice Minister Long Yong-Tu, China s lead WTO negotiator during a meeting in Hong Kong on November 28, 2001. Another benefit is the consequent domestic improvements in the rule of law.
} 
wealth of its citizens. Thus, broad consensus is essential for a move toward the rule of law, as opposed to rule by law: our analysis offers one reason why a consensus for incremental improvements might not be forthcoming in the vital arena of contract enforcement.

Two more complex political economy issues suggest themselves. Within a country, the tradeoff between the competing enforcement interests of importers and exporters (and producers of import-competing and export goods) could be analyzed within an interest group competition model (Grossman and Helpman, 1995). On the international front, negotiations over trade policy and enforcement occur both sequentially and simultaneously, raising the issue of whether contract enforcement and tariffs are substitutes or complements.

Our model does not formally distinguish public from private enforcement of contracts. Braudel (1992) presents many historical examples of ethnic networks that facilitate trust; see also recent empirical work by Rauch and Trindade (1999). Do effective private networks impede or complement the development of official enforcement? The domestic markets of buyers and sellers are exogenous in this paper, though we have hinted at connections between the formal protection extended to foreigners and subsequent domestic developments. A richer model of the domestic markets and the nature of enforcement should yield many insights. 


\section{References}

Acemoglu, Daron and Robert Shimer (1999), Holdup and Efficiency with Search Friction, International Economic Review, 40, 827-849.

Aitchison, J. and Brown and J.A.C. Brown (1957), The Lognormal Distribution, Cambridge; Cambridge University Press.

Anderson, James E. and Douglas Marcouiller (2001), Trade, Insecurity and Home Bias: An Empirical Investigation, Review of Economics and Statistics, forthcoming; revised version of NBER Working Paper No. 7000.

Anderson, James E. and Leslie Young (2000), Trade Implies Law: the Power of the Weak, NBER Working Paper No. 7702.

Bernard, Andrew B. and Joachim Wagner (1998), Export Entry and Exit by German Firms, NBER Working Paper No. 6538.

Binmore, Ken, Ariel Rubinstein and Asher Wolinsky (1986), "The Nash Bargaining Solution in Economic Modeling", Rand Journal of Economics, 17, 2, 176-88.

Braudel, Fernand (1992), The Wheels of Commerce, Berkeley: University of California Press.

Grossman, Gene and Elhanan Helpman (1995), Protection for Sale, American Economic Review, $\underline{84}, 833-850$.

Marcouiller, Douglas and Leslie Young (1995), The Black Hole of Graft: the Predatory State and the Informal Economy, American Economic Review 모, 630-646.

McLaren, John (1999), Supplier Relations and the Market Context: A Theory of Handshakes, Journal of International Economics, 48, 121-38.

Rauch, James R. and Vitor Trindade (1999), Ethnic Chinese Networks in International Trade, NBER Working Paper No. 7189.

Roberts, Mark and James Tybout (1997), The Decision to Export in Colombia: An Empirical Model of Entry with Sunk Costs, American Economic Review, 87, 545-564.

Rubinstein, Ariel (1982), Perfect Equilibrium in a Bargaining Model, Econometrica, 50, 97109.

Tirole, Jean (1999), Incomplete Contracts: Where Do We Stand?, Econometrica, 67, 74182. 
Weingast, Barry 1993 Constitutions as Governance Structures: The Political Foundations of Secure Markets, Journal of Institutional and Theoretical Economics 146, no. 1, 286-311.

World Economic Forum (1997), The Global Competitiveness Report 1997 (Geneva: World Economic Forum). 


\section{Proof of Lemma 1}

\section{Appendix A: Proofs}

(A) To apply Rolle s Theorem to (2.8), note that as $\mu \rightarrow \bar{\mu}, m(\mu) \rightarrow 0$ so $-\mu / m(\mu) \rightarrow \infty$. As $\mu \rightarrow$ $\underline{\mu},-\mu / m(\mu)$ becomes negative. Given a piecewise continuous probability density function $f(\mu),-\mu / m(\mu)$ is monotonic and continuous in $\mu$. Rolle s Theorem implies that there is a $\mu(\beta)$ between $\bar{\mu}$ and $\underline{\mu}$ satisfying (2.8). This is unique since $-\mu / m(\mu)$ is monotonic in $\mu$. For $\beta=0$, the requisite $\mu$ is $\bar{\mu}$. For $\beta=1$, the requisite $\mu$ is $0 . \mu(\beta)$ is monotonic and differentiable in $\beta$. (B) To apply Rolle s Theorem to (2.9), note that as $\beta \rightarrow 0$, (1- $\beta) / \beta \rightarrow \infty$ so the solution to (2.8) $\mu(\beta) \rightarrow \bar{\mu}$, and $(1-\beta) / F(\mu(\beta)) \rightarrow 1>1-\theta$ when $0<\theta$. As $\beta \rightarrow 1,(1-\beta) / \beta \rightarrow 0$, so $\mu(\beta) \rightarrow 0$, $F(\mu(\beta)) \rightarrow F(0)$ so $(1-\beta) / F(\mu(\beta)) \rightarrow 0<1-\theta$ when $\theta<1$ Moreover, $(1-\beta) / F(\mu(\beta))$ is continuous in $\beta$. Rolle $\mathrm{s}$ Theorem now implies that there exists a $\beta \in[0,1]$ satisfying (2.9). For $\theta=0$, the requisite $\beta$ is 0 . For $\theta=1$, the requisite $\beta$ is 1 .

\section{Proof of Lemma 2}

From the text, the objective probability of a match in an excess demand equilibrium is:

$$
\begin{aligned}
h(\pi, \beta) & =\frac{(1-\beta) s\left(p^{s}\right)}{d\left(p^{b}\right)-\beta s\left(p^{s}\right)} \text { where } \\
p^{s} & =\beta p^{b}+(1-\beta) p^{*}-m(\mu(\beta))(1-\beta)(1-\pi) \\
p^{b} & =\pi p^{*}+(1-\pi) b \\
p^{*} & =\omega b+(1-\omega) c .
\end{aligned}
$$

At an excess demand equilibrium, $d\left(p^{*}\right)>s\left(p^{*}\right)$. This implies that:

$$
h(1, \beta)=\frac{(1-\beta) s\left(p^{*}\right) / d\left(p^{*}\right)}{1-\beta s\left(p^{*}\right) / d\left(p^{*}\right)}<1
$$

Suppose that $\beta \in[0,1)$. As $\pi$ approaches 0 from above, $h(\pi, \beta)$ remains positive so that $h(\pi, \beta)>\pi$. Since $h(\pi, \beta)$ is continuous in $\pi$, Rolle s Theorem now implies that the equation

$$
\pi=h(\pi, \beta)
$$

has a solution $\pi[\beta]$ in the open interval $(0,1)$. This is unique since: 


$$
\begin{aligned}
& \frac{\partial p^{s}}{\partial \pi}=-\beta\left(b-p^{*}\right)+m(1-\beta) \leq 0 \\
& \frac{\partial p^{b}}{\partial \pi}=-\left(b-p^{*}\right)<0 \\
& h_{\pi}=\frac{\pi}{1-\beta}(1-\beta+\beta \pi)\left[\frac{\varepsilon^{s}}{p^{s}} \frac{\partial p^{s}}{\partial \pi}+\frac{\varepsilon^{b}}{p^{b}} \frac{\partial p^{b}}{\partial \pi}\right]<0
\end{aligned}
$$

Finally, when $\beta=1, p^{s}=p^{b}=p^{e}$ so (2.14) determines $\pi[1]$ as the solution to:

$$
p^{e}=p^{b}=\pi p^{*}+(1-\pi) b \text { so } \pi[1]=\frac{b-p^{e}}{b-p^{*}}
$$

Since $p^{e}<p^{*}$ in an excess demand equilibrium, $\pi[1] \in(0,1)$.

\section{Proof of Lemma 3}

A seller default victim expects the fallback option of a repudiator in re-negotiations to be $b+m$; on the spot market he expects to meet some buyers who entered directly whose fallback option in spot negotiations he expects to be $b$. Consequently, he expects a higher price in negotiations on the spot market than with the buyer who repudiated his contract. Specifically, he expects to negotiate a price with the repudiator of $p^{*}+\omega m$; in deriving (2.10), we showed that he would expect to achieve a higher price on the spot market of:

$$
p^{*}+\pi \omega m=\omega b+(1-\omega) c+\pi \omega m
$$

His expected gain from spot trade is $\omega(b-c+\pi m)+\underline{v}$, which is positive under hypothesis $(2.15)$

. Thus, he expects to do better than by returning home, which offers no gains from trade. Since the seller is always matched in an excess demand equilibrium, he expects a higher payoff from (i) entering the spot market than from (ii) renegotiating with the repudiator or (iii) returning home. It follows that (i) would be chosen by a victim faced with alternatives (ii) and (iii) without knowing the disturbance realized by the repudiator.

\section{Proof of Lemma 4}

(A) A seller who learns his cost disturbance $v$ expects to negotiate a price on the spot market equal to the price $p^{*}+\pi \omega m$ that he expected before learning his cost disturbance plus the increase $-v(1-\omega)$ in that negotiated price due to the disturbance of his cost from its 
expected value (which drives up his fallback option). This second term is certainly less than its value $-\underline{v}(1-\omega)$ under his worst (most negative) cost disturbance. Thus, the seller expects a higher price from honoring the contract than from a spot negotiation, provided that:

$$
p^{c}-\left(p^{*}+\pi \omega m\right)>-\underline{v}(1-\omega)
$$

(2.10) implies that:

$$
p^{s}-\left(p^{*}+\pi \omega m\right)=\beta\left[p^{c}-\left(p^{*}+\pi \omega m\right)\right]
$$

Substituting from (2.13) for $p^{s}-\left(p^{*}+\pi \omega m\right)$, we conclude that (8.4) holds provided that:

$$
\mu^{*}[(1-\pi)+\pi \omega /(1-\beta)]>-\underline{v}(1-\omega)
$$

Given hypothesis (2.16), this will be true because:

$$
(1-\pi) / \omega+\pi /(1-\beta)>1
$$

(B) An argument similar to that for Lemma 3 shows that if (2.15) holds, then a seller who enters the spot market expects higher profits than by returning home. Thus, if both (2.15) and (2.16) hold, then the seller expects more from honoring his contract than from returning home.

Next, consider what a seller expects from repudiating his contract and renegotiating with his victim. His victim will require a price no less than what he expects to negotiate on the spot market. His required price will depend on his benefit disturbance. The seller would not know this benefit disturbance when he repudiates the contract; his expectations would be based on the distribution of benefit disturbances across buyers. The seller rationally expects any renegotiation to extract no more than the price $p^{b}$ that buyers themselves expect to negotiate on the spot market before they learn their benefit disturbance. (2.7) implies that in equilibrium, this is less than the contract price $p^{C}$. Thus, a seller expects more from honoring his contract than from renegotiating with his victim.

\section{Proof of Proposition 1:}

This follows immediately from Lemmas 1- 4. 


\section{Proof of Lemma 5}

To compute how $\beta$ affects $\mu(\beta)$, differentiate (2.8) logarithmically with respect to $\beta$ and apply the Fundamental Theorem of Calculus to $m(\mu(\beta))=\int_{\underline{\mu}}^{\mu(\beta)} \mu f(\mu) d \mu$ :

$$
\left[\frac{\mu f}{m}-\frac{1}{\mu}\right] \mu_{\beta}=\frac{1}{\beta}+\frac{1}{1-\beta}=\frac{1}{\beta(1-\beta)}
$$

At $\mu=\mu(\beta)>0$, we have $\_<$, so $\mu_{\beta}<0$ and:

$$
m_{\beta}=\mu f \mu_{\beta}<0
$$

\section{Proof of Lemma 6}

(A) Differentiating (2.9) logarithmically, we infer that $\beta_{\theta}$ has the sign of:

$$
-\frac{g_{\beta}}{g}=\frac{1}{1-\beta}+\frac{f \mu_{\beta}}{F}
$$

Substituting from (2.9) and (8.6), this has the same sign as:

$$
\beta F\left[\frac{\mu f}{-m}+\frac{1}{\mu}\right]-f=\frac{-m F}{-m+\mu}\left[\frac{1}{\mu}+\frac{\mu f}{-m}\right]-f \text { by (2.8) }
$$

This has the same sign as:

$$
\mu f(-m+\mu)-m F-\mu^{2} f F=-m(F-\mu f)-\mu^{2} f(1-F)
$$

This is negative at $\mu$ provided that (3.1) holds.

$g(1)=0$ and $g(0)=1$. If $g(\beta)>1$ for $\beta$ close to 0 , then by Rolle s Theorem, there is some $\beta_{4}<1$ such that $g\left(\beta_{4}\right)=1$ (see Figure 1[d]). An increase in $\theta$ past 0 would then lead to an upward jump in $\beta(\theta)$ to $\beta_{4}$. Next, suppose that $g(\beta) \leq 1$ for $\beta$ close to 0 . Given hypothesis (3.1) , let $\beta$ be the value of $\beta$ such that $\mu(\beta)=\mu$. Then (8.8) and (3.1) ensure that $g_{\beta}(\beta)>0$. If $g(\beta)<1$, then set $\theta=1-g(\beta)$ (see Figure $1[\mathrm{~b}]$ ). Now suppose that $g(\beta) \ddagger 1$. Under our maintained hypothesis that $g(\beta) \leq 1$ for $\beta$ close to 0 , the graph of $g(\beta)$ starts from $\beta=0$ at a height of 1 , initially falls, then turns and rises at least to the height of 1 at $\mu$, where it is 
positively sloped. Therefore, the graph must have a positive slope at some $\beta<\beta$ where its height is less than 1, i.e., $g_{\beta}(\beta)>0$ and $g(\beta)<1$. Set $\theta=1-g(\beta)$ (see Figure 1[c]).

(B) The first part of (B) follows immediately from the first paragraph of the proof of (A). Suppose that $\mu$ is uniformly distributed between $-\mathrm{w}$ and $\mathrm{w}$ for some constant $\mathrm{w}$. Then:

$$
m(\mu)=(\mu-w) / 2, F(\boldsymbol{\mu}=(w+\mu) / 2 w .
$$

(2.8) becomes:

$$
\begin{aligned}
& \frac{2 \mu}{\mu-w}=\frac{1-\beta}{\beta} \\
& \mu(\beta)=w \frac{1-\beta}{1+\beta} \text { and } F(\mu(\beta))=\frac{1}{1+\beta}
\end{aligned}
$$

(2.9) becomes:

$$
1-\theta=(1-\beta) / F(\mu(\beta))=1-\beta^{2}
$$

so $\beta(\theta)=\sqrt{\theta}$.

\section{Proof of Lemma 7}

The density function of the lognormal variate $z$ is:

$$
\phi(z)=\frac{1}{z \sigma \sqrt{2 \pi}} \exp \left\{-\frac{1}{2}\left(\frac{\ln z-M}{\sigma}\right)^{2}\right\}
$$

where $M$ and $\sigma^{2}$ are the mean and variance of $\ln z$. The expected value of $\mathrm{z}$ is $\exp \left(M+\sigma^{2} / 2\right)$. $\mu$ $=\bar{\mu}-z$ has mean 0 so:

$$
\exp \left(M+\sigma^{2} / 2\right)=\bar{\mu}
$$

The maximum of $\phi(z)$ is attained at $z \equiv \exp \left(M-\sigma^{2}\right)$. For $\mu=\bar{\mu}-z$ :

$$
\begin{aligned}
& \mu f(\mu)=\phi(z)(\bar{\mu}-z)= \\
& =\frac{1}{\sigma \sqrt{2 \pi}} \exp \left\{-\frac{\sigma^{2}}{2}\right\}\left[\frac{\bar{\mu}}{z^{\prime}}-1\right]=\frac{1}{\sigma \sqrt{2 \pi}}\left[\exp \left\{\sigma^{2}\right\}-\exp \left\{-\frac{\sigma^{2}}{2}\right\}\right] \text { by (8.9) and (8.1) }
\end{aligned}
$$

For large $\sigma$, this is greater than 1 , so (3.1) holds when the density of $\mathrm{z}$ is lognormal throughout its support. 
Suppose that we exclude negative gross buyer benefits by truncating the distribution of $z$ at the level $z_{0}$ that would yield zero benefits, compressing the probability mass from the right tail into a spike at $z_{0}$. This does not affect the cumulative probability function for $z$ less than $z_{0}$, but the resulting reduction in the mean of the distribution of $z$ must be added to $m(\mu)$. This adjustment affects only the cutoff value of $\sigma$ at which (3.1) is attained.

\section{Proof of Lemma 8}

With the change of variable $z=\bar{\mu}-\mu$ we have:

$$
-m(\mu ; M, \sigma)=\int_{0}^{\bar{\mu}-\mu}(\bar{\mu}-z) \phi(z) d z
$$

Let $N($.) be the cumulative standard normal density. Exploiting standard properties of the moment distributions of the lognormal variate $z$ (Aitchison and Brown, Theorem 2.4, p.12):

$$
\begin{aligned}
& 1-\frac{m(\mu ; M, \sigma)}{\mu}=\left[1+\frac{\bar{\mu}}{\mu}\left\{N\left(\frac{\ln (\bar{\mu}-\mu)-M}{\sigma}\right)-N\left(\frac{\ln (\bar{\mu}-\mu)-M-\sigma^{2}}{\sigma}\right)\right\}\right] \\
& F(\mu ; M, \sigma)=1-N\left(\frac{\ln (\bar{\mu}-\mu)-M}{\sigma}\right)
\end{aligned}
$$

These equations allow us to trace numerically the graph of $G(\mu ; 0, \sigma)$ for each possible $\sigma$, confirming [a] - [d] when $M=\mathscr{F o r} \sigma$ in the intervals $(0, .58]$, [.59,.62],[.63,1.48],[1.49, $\infty)$. For other values of $M$, the graph of $G(\mu ; M, \sigma)=G(\mu \exp (M) ; 0, \sigma)$ can be derived from that of $G(\mu ; 0, \sigma)$ by applying a positive monotonic transformation to the $(G, \mu)$ plane along the $\mu$ dimension. Such a transformation does not affect properties [a] - [d].

Since $\mu(\beta)$ is a (negative) monotonic function, the graph of $g(\beta)=G(\mu(\beta) ; M, \sigma)$ can be obtained from that of $G(\mu ; M, \sigma)$ by applying a negative monotonic transformation to the $(G$, $\mu$ ) plane along the $\mu$ dimension. This leads to Figures $1[\mathrm{a}]-[\mathrm{d}]$. The range of giving rise to each case is that which gave rise to the corresponding graph of $G(\mu ; 0, \sigma)$.

For $\mu$ in the interval $[0, \bar{\mu}]$, the adjustment used at the end of the proof of Lemma 7 to exclude negative buyer benefits does not affect the cumulative probability function (8.12); in 
(8.11) it adds a constant term to $m(\mu ; M, \sigma)$. This shifts the cutoff values of $\sigma$ defining cases [a]

— $[\mathrm{d}]$, but does not alter the Lemma s overall conclusion.

\section{Proof of Lemma 9}

Differentiating the equation (8.1) defining $\pi$ with respect to $\theta$ yields:

$$
\frac{d \pi}{d \beta}=\frac{h_{\beta}}{1-h_{\pi}}
$$

Also:

$$
\frac{d p^{s}}{d \beta}=\frac{\partial p^{s}}{\partial \beta}+\frac{\partial p^{s}}{\partial \pi} \frac{d \pi}{d \beta}
$$

Substituting from (8.13) and rearranging:

$$
\frac{d p^{s}}{d \beta}\left(1-h_{\pi}\right)=\frac{\partial p^{s}}{\partial \beta}\left(1-h_{\pi}\right)+\frac{\partial p^{s}}{\partial \pi} h_{\beta}
$$

But:

$$
h_{\beta}=\left[-(1-\pi)+(1-\beta+\beta \pi) \frac{\varepsilon^{s}}{p^{s}} \frac{\partial p^{s}}{\partial \beta}\right] \frac{\pi}{1-\beta}
$$

Therefore:

$$
\frac{d p^{s}}{d \beta}\left(1-h_{\pi}\right)=\frac{\partial p^{s}}{\partial \beta}\left[1-\frac{\pi}{1-\beta}(1-\beta+\beta \pi) \frac{\varepsilon^{b}}{p^{b}} \frac{\partial p^{b}}{\partial \pi}\right]-\frac{\partial p^{s}}{\partial \pi} \frac{\pi(1-\pi)}{1-\beta}
$$

By Lemma 5 and (8.2):

$$
\begin{aligned}
& \frac{\partial p^{s}}{\partial \beta}=(1-\pi)\left(b+m-p^{*}\right)-(1-\beta)(1-\pi) m_{\beta}>0 \\
& \frac{\partial p^{s}}{\partial \pi}=-\beta\left(b-p^{*}\right)+(1-\beta) m \leq 0 \\
& 1-h_{\pi}>0
\end{aligned}
$$

The conclusion that $\frac{d p^{s}}{d \beta}>0$ now follows from (8.15).

\section{Proof of Proposition 3}

Holding constant the probability $\pi$ of a match, the marginal impact of $\beta$ on $X$ is:

But:

$$
\frac{\partial X}{\partial \beta}=(b-q) s_{p}\left(p^{s}\right) p_{\beta}^{s}-s q_{\beta}^{s}=q_{\beta}^{s} s\left\{\varepsilon^{s} \frac{b-q^{s}}{q^{s}} \Delta[\theta]-1\right\}
$$




$$
q_{\beta}^{s}=\left(b-p^{*}\right)(1-\pi)>0
$$

The proof is completed by showing that:

$$
\frac{d x}{d \beta} \text { has the sign of } \frac{\partial X}{\partial \beta}
$$

We have:

$$
X \equiv x d(b-x)=\left(b-p^{*}\right)(1-\beta+\beta \pi) s\left(p^{s}\right) \equiv H(\beta, \pi(x))
$$

Differentiating this with respect to $\beta$, recognizing that $\mathrm{x}$ is also a function of $\beta$ :

$$
\begin{aligned}
& X_{x} \frac{d x}{d \beta}=H_{\beta}+H_{\pi} \pi_{x} \frac{d x}{d \beta} \\
& \left(X_{x}-H_{\pi} \pi_{x}\right) \frac{d x}{d \beta}=H_{\beta}
\end{aligned}
$$

Thus, $\frac{d x}{d \beta}$ has the sign of $H_{\beta}$ provided that:

$$
0<X_{x}-H_{\pi} \pi_{x}=d-x d_{p^{-}}\left(b-p^{*}\right) \pi_{x}\left\{\beta s+(1-\beta+\beta \pi) s_{p} p_{\pi}^{s}\right\}
$$

But $\left(b-p^{*}\right) \pi_{x}=1$ so this is true provided that:

$$
0<X_{x}-H_{\pi} \pi_{x}=d-x d_{p}+\left\{-\beta s+(1-\beta+\beta \pi) s_{p}\left[\beta\left(b-p^{*}\right)-(1-\beta) m\right]\right\} \text { by }(8.16)
$$

This is always true since $d \neq \beta$. $\|$

\section{Proof of Lemma 10}

(A) By Lemma 1A, as $\beta \rightarrow 0$, and $\mu(\beta) \rightarrow \bar{\mu}$ so $-m(\mu(\beta)) \rightarrow 0 \cdot p^{s} \rightarrow p^{*}$ and $p^{b} \rightarrow p^{*}$ so $r$ $\rightarrow 0$ and $q^{s} \rightarrow p^{*}$. For the behavior of $-m_{\beta}(\mu(\beta))$, substitute from (8.6) into (8.7) to obtain:

$$
m_{\beta}=\frac{-\mu f}{\left[\frac{\mu f}{m}-\frac{1}{\mu}\right] \beta(1-\beta)}=\frac{\mu f \mu}{\left[\mu f(1-\beta)^{2}+\beta(1-\beta)\right]} \text { by (2.8) }
$$

Then $-m_{\beta}(\mu(\beta)) \rightarrow \bar{\mu}$ so $r_{\beta} \rightarrow(1-\pi[0]) \bar{\mu}, q_{\beta} \rightarrow\left(b-p^{*}\right)(1-\pi[0])$ and $\Delta[\beta] \rightarrow 1+\bar{\mu} /\left(b-p^{*}\right){ }^{13}$

(B) By Lemma 1A, as $\beta \rightarrow 1, \mu(\beta) \rightarrow 0,-m(\mu(\beta)) \rightarrow-m(0), r \rightarrow 0$ and $r / q \rightarrow 0$. By (8.18) 
$-m_{\beta} \rightarrow 0$, so $r_{\beta} \rightarrow(1-\pi[1]) m(0)$ and $q_{\beta} \rightarrow(1-\pi[1])\left(b-p^{*}\right)$ so $r_{\beta} / q_{\beta} \rightarrow m(0) /\left(b-p^{*}\right)$ and $\Delta[\beta] \rightarrow 1+m(0) /\left(b-p^{*}\right) \cdot p^{s} \rightarrow p^{e}$.

\section{Proof of Lemma 12}

In an excess demand equilibrium at price $p^{*}\left(<p^{e}\right)$ expected gross profits per buyer are:

$$
x\left(p^{*}\right)=\left(b-p^{*}\right),{ }^{*}=x[0]
$$

where $\pi^{*}$ is the solution to $\pi=s\left(p^{*}\right) / d\left(\left(p^{*}-b\right),,+b\right)$. Under perfect enforcement, expected gross profits per buyer are:

$$
x\left(p^{e}\right)=b-p^{e}=x[1]
$$

Aggregate buyers gross profits at prices $p^{*}$ and $p^{e}$ are:

$$
\begin{aligned}
& X\left(p^{*}\right)=\left(b-p^{*}\right) s\left(p^{*}\right)=x\left(p^{*}\right) d\left(b-x\left(p^{*}\right)\right)=x[0] d(b-x[0]) \\
& X\left(p^{e}\right)=\left(b-p^{e}\right) s\left(p^{e}\right)=x\left(p^{e}\right) d\left(b-x\left(p^{e}\right)\right)=x[1] d(b-x[1])
\end{aligned}
$$

Since $x d(b-x)$ is increasing in $x$, the Lemma follows immediately.

\section{Proof of Lemma 13}

By (3.4):

$$
q^{s} / p^{s}<\Delta[\theta] \text { if and only if } p_{\beta}^{s}>q_{\beta}^{s} \text {, i.e., if and only if } 0<r_{\beta}
$$

In proving Lemma 10 we showed that as $\beta \rightarrow 0, r_{\beta} \rightarrow \bar{\mu}>0$; as $\beta \rightarrow 1, r_{\beta} \rightarrow(1-\pi) m(0)<0$.

\section{Appendix B: Alternative Trading Mechanisms.}

Suppose that the victim of a repudiated, unenforced contract cannot renegotiate with anyone but is thrown back onto his domestic market. Buyers and sellers then expect prices:

$$
\begin{aligned}
& p^{b}=\beta p^{c}+(1-\beta) b \\
& p^{s}=\beta p^{c}+(1-\beta) c .
\end{aligned}
$$

The contract price is determined by the equilibrium condition:

$$
d\left(\beta p^{C}-(1-\beta) b\right)=s\left(\beta p^{C}+(1-\beta) c\right) .
$$

\footnotetext{
${ }^{13}$ Sellers approach indifference to holding contracts as $\beta \rightarrow 0$, but we preserve continuity by assuming they hold contracts of vanishingly small value.
} 
Trade would be inefficient because there is a gap between the buyers' and sellers' prices. Increases in $\beta$, the probability of execution, would raise trade volume and increase trader rents on both sides of the market, hence all agents would prefer better enforcement.

Suppose that the victim can renegotiate only with the repudiator. So long as the probability of execution is positive, the contracting market will clear at a contract price such that $d\left[b-\beta p^{C}-(1-\beta) p^{*}\right]=s\left[\beta p^{C}+(1-\beta) p^{*}-c\right]$. For any $\beta>0$, the effect of increases in enforcement is only distributional. Note that trade is efficient in this model: imperfect enforcement is thus another environment where adding a market reduces efficiency.

Can repudiators remove the incentive for victims to search by private action? The answer is no. In excess demand equilibrium, the buyer who defaults can offer the seller an advance payment to renegotiate rather than search. At the average cost disturbance for default, the buyer could afford to pay up to $(1-\pi) \omega m$. For buyers with sufficiently favorable realizations of the cost disturbance process, such a payment is feasible. But for many defaulting buyers, their realization of the disturbance is insufficiently favorable (such as those in the interval $\left.\left[m, \mu^{*}\right]\right)$. Moreover, any buyer who could afford to make such an offer signals to the seller that his disturbance is even better. Thus, advance payment of this type is unable to prevent a spot market. A more involved question is whether the excess side can commit advance payment at the contract stage which is sufficient to achieve efficient trading. It turns out to be impossible to simultaneously reach efficient trade and yet ensure that the advance payment to the putative scarce side does not induce them to default. Proof is available on request. 
Figure 1: Impact of enforcement $\theta$ on contract execution $\beta(\theta)$ [also on seller s profits and on buyer s profits $x[\beta(\theta)]$ when $\left.x_{\beta}>0\right]$

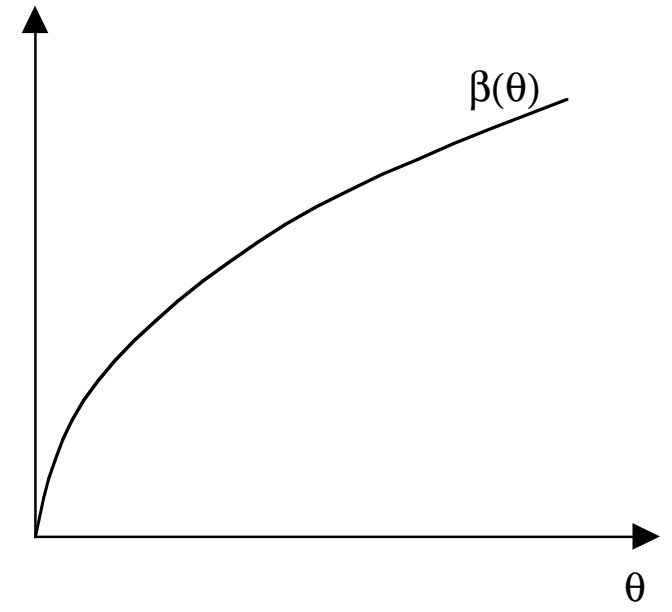

[a] e.g., uniform buyer disturbances or lognormal disturbances with $\sigma \leq 0.58$

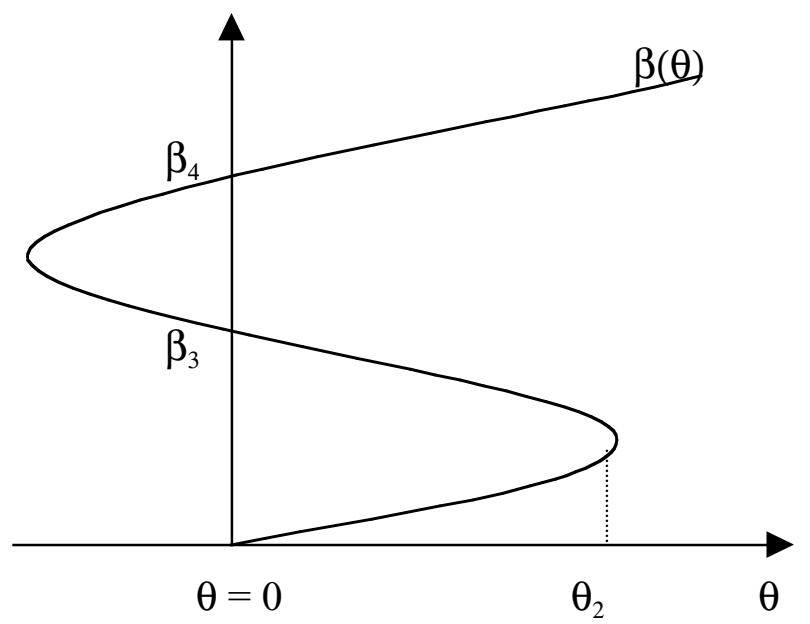

[c] e.g., lognormal buyer disturbances with $0.63 \leq \sigma \leq 1.48$

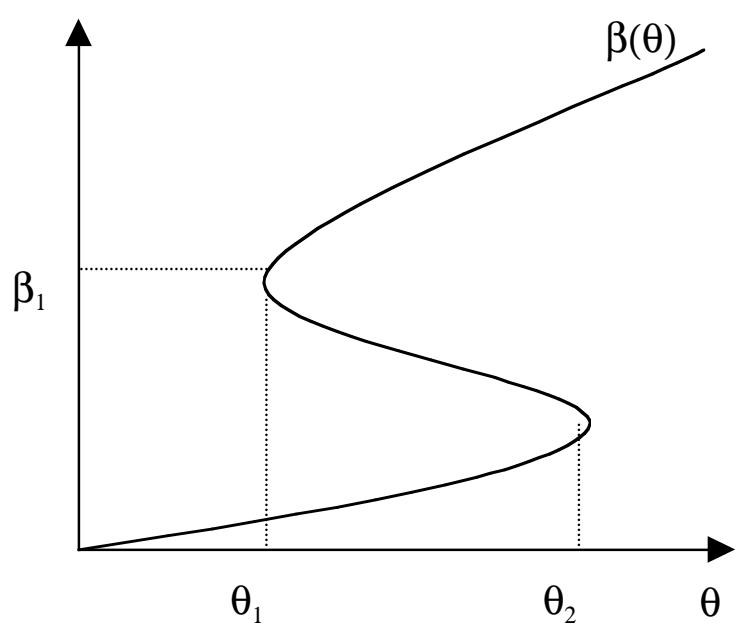

[b] e.g., lognormal buyer disturbances with $0.59 \leq \sigma \leq 0.62$

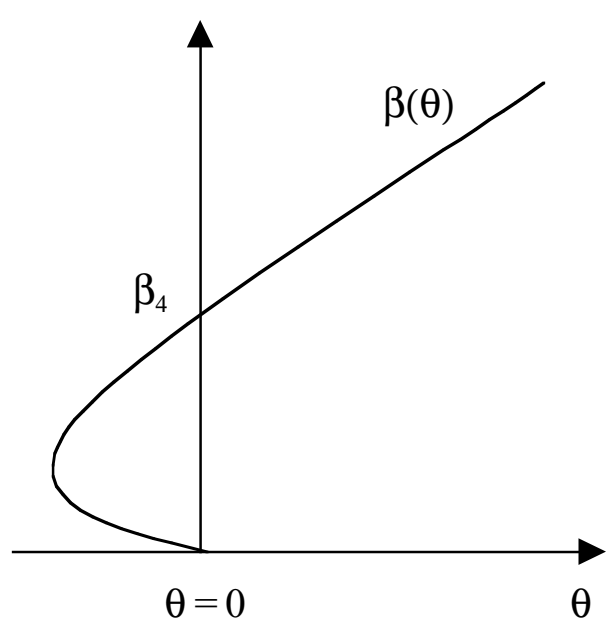

[d] e.g., lognormal buyer disturbances with $1.49 \leq \sigma$ 
Figure 2: Impact of contract execution $\beta$ on buyer s profits $x[\beta]^{*}$
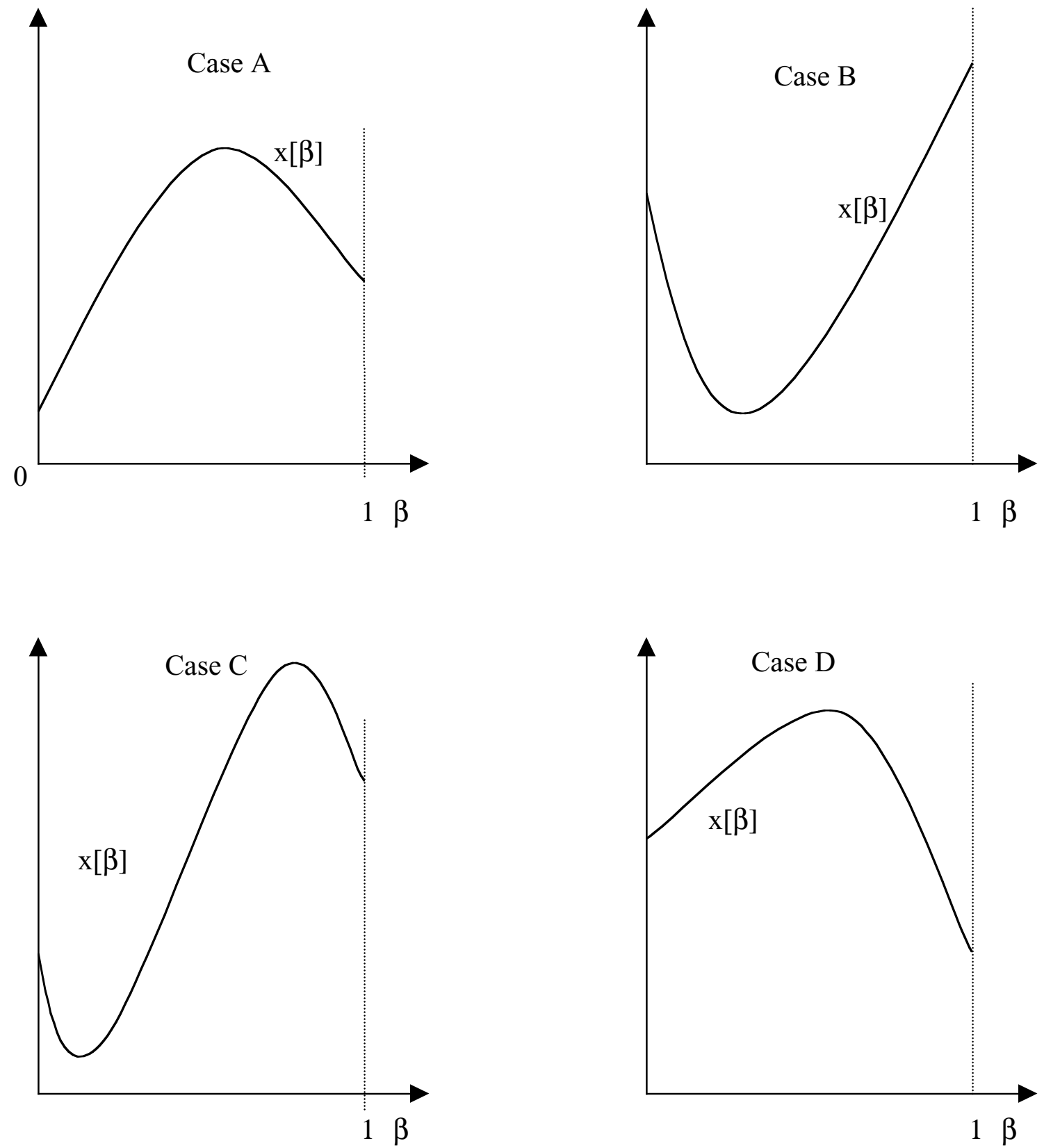

\footnotetext{
* In simulations with a uniform distribution of trading costs over buyers and sellers, hence linear demand and supply curves, case A obtains.
} 
Figure 3: Impact of enforcement $\theta$ on buyer s profits $x[\beta(\theta)]$ when $x_{\beta}<0$.

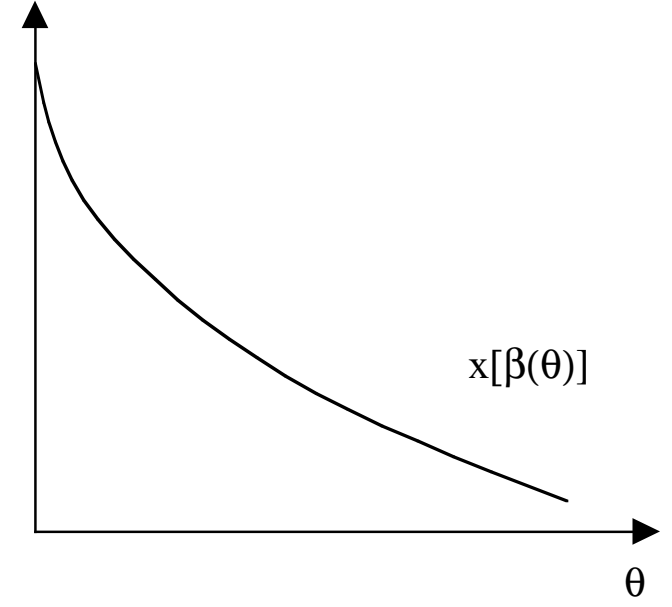

[a] e.g., uniform buyer disturbances or lognormal disturbances with $\sigma \leq 0.58$

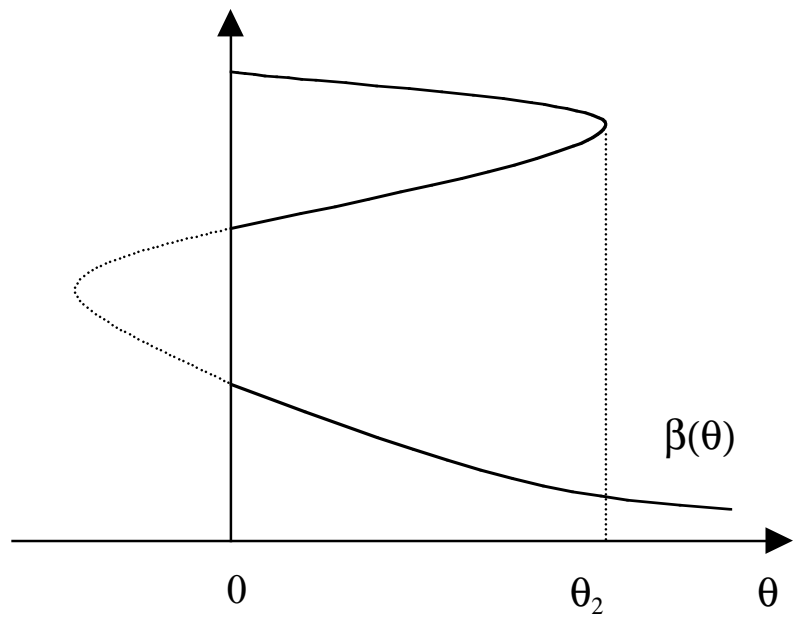

[c] e.g., lognormal buyer disturbances with $0.63 \leq \sigma \leq 1.48$

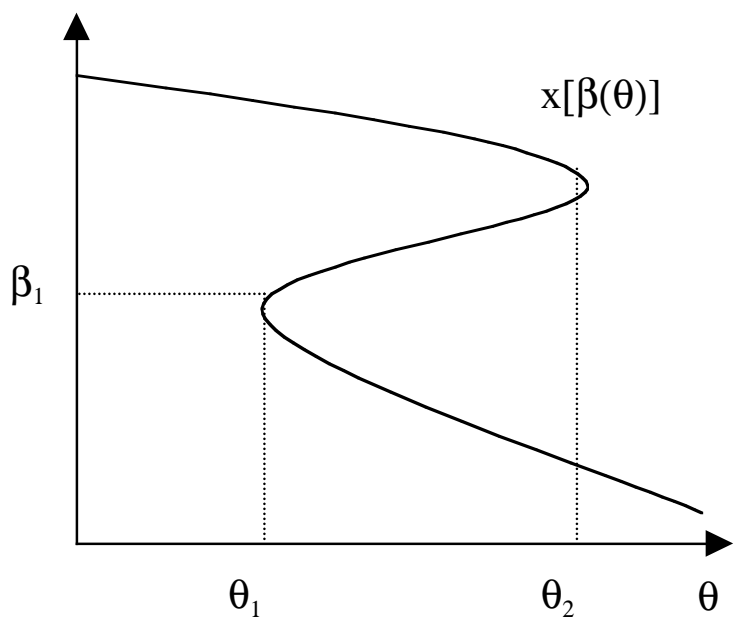

[b] e.g., lognormal buyer disturbances with $0.59 \leq \sigma \leq 0.62$

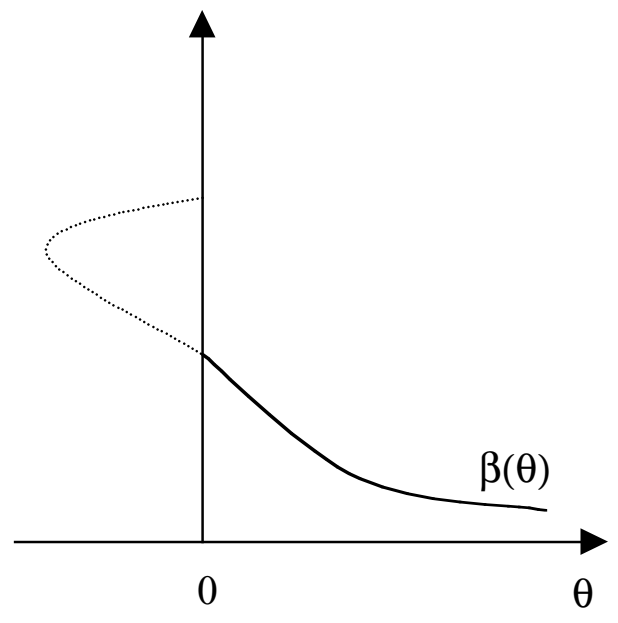

[d] e.g., lognormal buyer disturbances with $1.49 \leq \sigma$ 